\title{
Phenotypes and Pathophysiology of Syndromic Hidradenitis Suppurativa: Different Faces of the Same Disease? A Systematic Review
}

\author{
Georgios Nikolakis ${ }^{a, b}$ Katarzyna P. Kaleta ${ }^{a, c}$ Aristeidis G. Vaiopoulos ${ }^{a}$ b \\ Katja Wolter ${ }^{a}$ Sumer Baroud ${ }^{a}, d$ Anna Wojas-Pelc ${ }^{c}$ Christos C. Zouboulis ${ }^{a}$ b \\ ${ }^{a}$ Departments of Dermatology, Venereology, Allergology, and Immunology, Dessau Medical Center, \\ Brandenburg Medical School Theodor Fontane, Dessau, Germany; ${ }^{b}$ European Hidradenitis Suppurativa Foundation \\ e.V., Dessau, Germany; ${ }^{C}$ Department of Dermatology, Jagiellonian University Medical College, Krakow, Poland; \\ dUniversity of Sharjah, Sharjah, United Arab Emirates
}

\section{Keywords}

Hidradenitis suppurativa $\cdot$ Acne inversa . Syndrome .

Arthritis - Synovitis-acne-pustulosis-hyperostosis-osteitis . Inflammatory bowel disease - Autoinflammatory disorder . Pustulosis

\begin{abstract}
Background: There is growing evidence that (certain) hidradenitis suppurativa (HS) comorbidities comprise syndromes including HS as a key cutaneous manifestation. These apparently autoinflammatory syndromes and their diagnostic delay might have detrimental effects on affected patients. Methods: A systematic review was performed on the databases MEDLINE, EMBASE, and CENTRAL utilizing a standardized extraction form according to the Preferred Reporting Items for Systematic Reviews and Meta-Analyses (PRISMA) guidelines. Results: Sixty-four eligible articles on syndromic HS were retrieved. The identified syndromes included already described ones (pyoderma gangrenosumacne-suppurative hidradenitis, pyogenic arthritis-pyoderma gangrenosum-acne-suppurative hidradenitis, psoriatic arthritis-pyoderma gangrenosum-acne-suppurative hidradenitis, pyoderma gangrenosum-acne vulgaris-hidradenitis
\end{abstract}

suppurativa-ankylosing spondylitis, synovitis-acne-pustulosis-hyperostosis-osteitis) and further novel symptom constellations. Cutaneous signs, including HS lesions, usually precede signs from other organs. The cutaneous signs of a considerable proportion of patients appear refractory to conventional treatment, and monotherapy with biologics does not suffice to sustain remission. Conclusion: The results are subsequently discussed with focus on the pathophysiology and treatment of the detected syndromes. The dermatologist's role in the precise diagnosis and early treatment administration of $\mathrm{HS}$ is pivotal. The purpose of the treatment should be the effective prevention or delay of the autoinflammatory march and its irreversible consequences.

(c) 2020 S. Karger AG, Basel

\section{Introduction}

Hidradenitis suppurativa (HS), or acne inversa, is a chronic inflammatory skin disease of the hair follicle characterized by painful, deep-seated, recurrent nodules and abscesses, mostly in the apocrine-bearing localiza-

G. Nikolakis and K.P. Kaleta contributed equally to the manuscript. karger@karger.com

(c) 2020 S. Karger AG, Basel

www.karger.com/drm

Karger!
Georgios Nikolakis

Departments of Dermatology, Venereology, Allergology, and Immunology

Dessau Medical Center, Brandenburg Medical School Theodor Fontane

Auenweg 38, DE-06847 Dessau (Germany)

nikolakisgeorgios@gmail.com 
tions of the body, namely the axillary, inguinal, and anogenital regions (Dessau definition) $[1,2]$. The initial inflammatory lesions rupture and lead to scarring and/or sinus tract formation [3]. The detected prevalence of the disease varies between 0.03 and $0.53 \%$, whereas a prevalence up to $1 \%$ has been suggested [4-6]. HS mostly manifests during or after puberty.

In addition to its occurrence as a single disease, HS can also be a cardinal manifestation or an optional feature of certain syndromes recognized through their unique phenotypic constellation [7]. Syndromic HS has been included in the group of the so called autoinflammatory diseases.

Autoinflammatory diseases are characterized by recurrent sterile inflammation with lack of high autoantibody titers or antigen-specific $\mathrm{T}$ lymphocytes. They are caused by a dysregulation of innate immunity [8-12] and involve a series of cutaneous and multiorgan diseases [13]. The cutaneous involvement in autoinflammation is usually marked by accumulation of neutrophils. Apart from the classic neutrophilic dermatoses, such as pyoderma gangrenosum (PG), Sweet's syndrome, palmoplantar pustulosis, and erythema elevatum et diutinum, other dermatoses, including HS, share similarly increased levels of proinflammatory chemokines and cytokines with autoinflammatory diseases [14-19]. The majority of autoinflammatory disorders are characterized by overproduction of interleukin- $1 \beta$ (IL- $1 \beta$ ), which triggers the release of tumor necrosis factor alpha (TNFa) and interferon gamma, being subsequently responsible for neutrophil recruitment and activation as well as evasion of apoptosis [20-23].

IL-17 also contributes to neutrophil recruitment and activation and acts in synergy with other cytokines, such as TNFa [24]. A dysregulation of the regulatory T/T helper 17 cell ratio is believed to play a role in aggravating the autoinflammatory response and has been detected both in PG and HS independently [25-27].

PG, HS, acne conglobata, acne fulminans, palmoplantar pustulosis, inflammatory bowel disease (IBD; including Crohn's disease [CD] and ulcerative colitis [UC]), musculoskeletal disorders (arthritis, synovitis, osteitis, hyperostosis, axial spondyloarthropathy), and ocular symptoms are the most common diseases/clinical signs reported in syndromic HS cases. Combinations of the aforementioned diseases/clinical signs led to the description of HS-related autoinflammatory syndromes: pyoderma gangrenosum-acne-suppurative hidradenitis (PASH), pyogenic arthritis-pyoderma gangrenosum-acne-suppurative hidradenitis (PAPASH), pyoderma gan- grenosum-acne vulgaris-hidradenitis suppurativa-ankylosing spondylitis (PASS), and psoriatic arthritis-pyoderma gangrenosum-acne-suppurative hidradenitis (PsAPASH). Moreover, the synovitis-acne-pustulosishyperostosis-osteitis (SAPHO) syndrome comprises a combination of cutaneous and articular symptoms including HS, although pustulosis is listed in the acronym as the main cutaneous sign.

The purpose of this review is to detect common clinical denominators of the different HS-associated syndromes and their current treatment in order to further broaden the scientific clinical spectrum of dermatologists so that they can actively search, diagnose, and treat syndromic forms of HS. Moreover, it attempts to recognize demographic characteristics of prevalence, phenotype, and order of organ manifestations in order to provide the scientific basis over indicated therapy options before the development of the whole syndromic, sometimes irreversible, symptoms palette. Lastly, it underlines the effective role of dermatology experts as coordinators in the multidisciplinary approach to the patient.

\section{Methods}

The initial search was conducted in the electronic databases MEDLINE, EMBASE, and CENTRAL using a set of relevant search terms: "hidradenitis," "suppurativa," "acne inversa," "autoinflammatory," "synovitis," "acne," "pustulosis," "hyperostosis," "osteitis," "arthritis," "pyoderma gangrenosum," "spondylitis," and "psoriasis." Subsequently, the references of the aforementioned articles were also screened for eligibility. Eligible studies were considered clinical trials, cross-sectional studies, cohort studies, case series, case reports, and letters to the editor, where HS was referred to manifest with at least two other organ systems involved (i.e., musculoskeletal and gastrointestinal) including but not limited to arthritis, synovitis, osteitis, hyperostosis, ankylosing spondylitis, PG, CD or UC, acne vulgaris, and dissecting folliculitis. Excluded were reports only describing cutaneous signs of the follicular tetrad (acne, HS, pilonidal sinus, dissecting folliculitis of the scalp); articles in languages other than English, German, Polish, or Greek, and articles concerning paradoxical reactions to biologic drugs, as symptom development could not be definitively attributed to the initial disease manifestations that reoccur due to a loss of response to the biologic compound. Cases of familial Mediterranean fever, although inflammatory in nature, were not included as familial Mediterranean fever comorbidity with HS is controversial [28-30].

A standardized and predetermined extraction form (decided by G.N., K.P.K., and C.C.Z.) was used to extract information from each eligible study by two independent reviewers (G.N. and K.P.K.). Demographic data, phenotype characteristics, and treatment outcomes were recorded and separately confirmed. A Preferred Reporting Items for Systematic Reviews and Meta-Analyses 
Fig. 1. Preferred Reporting Items for Systematic Reviews and Meta-Analyses (PRISMA) chart describing the methodologic approach. FMF, familial Mediterranean fever; HS, hidradenitis suppurativa.
PubMed (MEDLINE), EMBASE, CENTRAL incl. references $(n=463)$

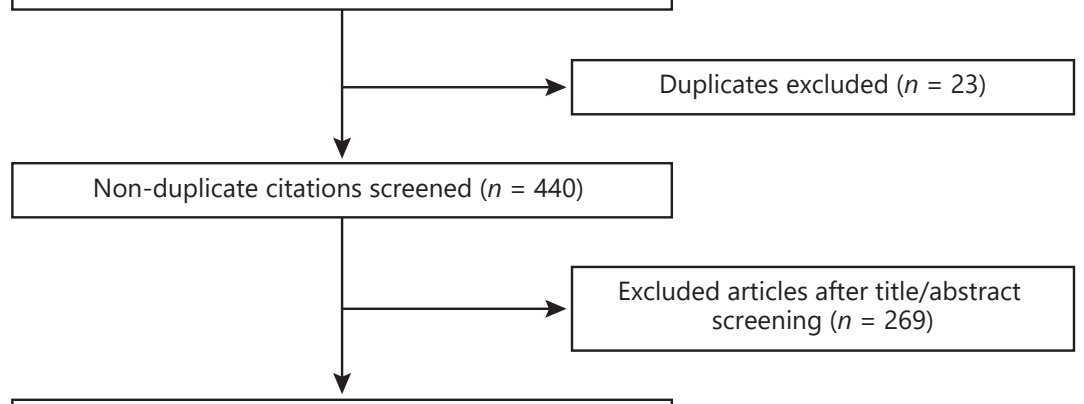

Full-text articles assessed for eligibility $(n=171)$

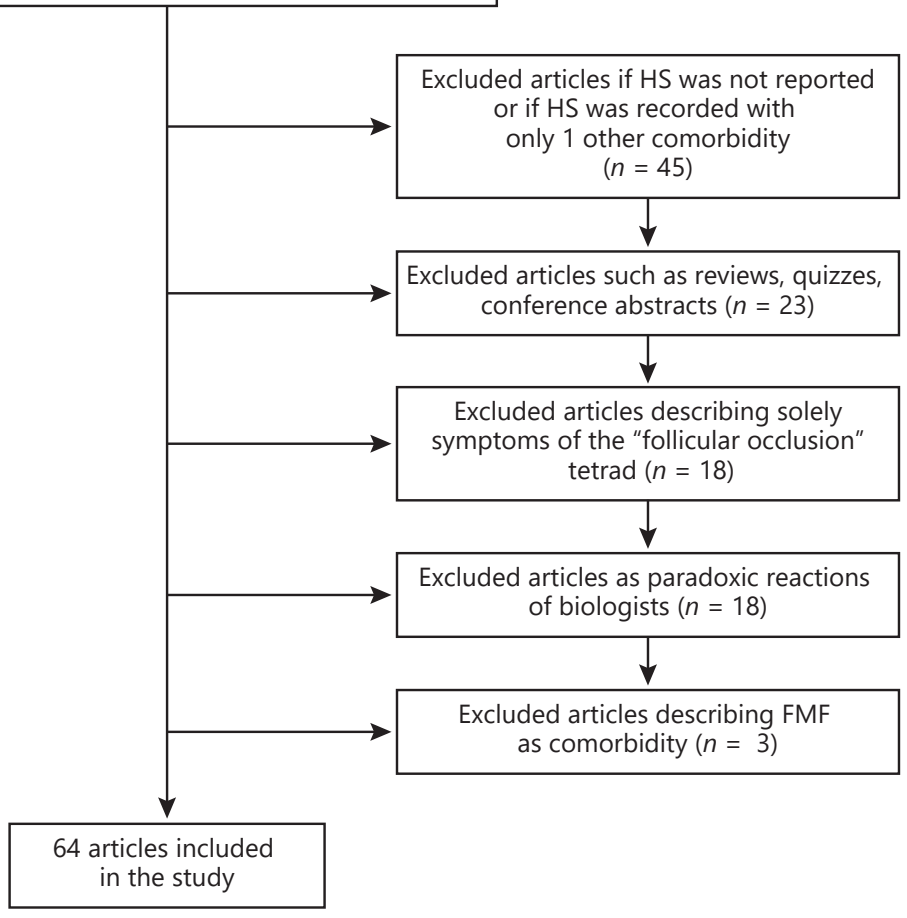

(PRISMA) chart describing the methodologic approach is presented in Figure 1.

A total of 64 articles were determined eligible and thus included in our study. Thirty-five articles concern 56 patients with one of the following syndromes: PASH, PAPASH, PsAPASH, or PASS. Additionally, 13 articles reporting HS as a part of SAPHO syndrome in 21 individuals were identified. One of those patients had overleaping features of PASH and SAPHO, for whom the article was included in both aforementioned categories, but not counted twice. Finally, 17 articles described 30 patients where HS was accompanied by a minimum of two other inflammatory diseases/organs involved. One of those articles described 1 additional patient who had PASH syndrome. According to our methodology, there have been 107 patients with syndromic HS reported so far.

\section{PASH, the "Leading" Player in a HS-Associated Autoinflammatory Syndrome Team with a Still Unsolved Genetic Background}

\section{Results}

The great majority (almost $40 \%$ ) of the cases identified through the literature search is represented by patients diagnosed with PASH syndrome, with a mean age at the time of diagnosis of 33.7 years and a significant male predominance (64\%). Body mass index data were only reported in 20 out of 39 patients with $\mathrm{PASH}$, with equal numbers of patients exhibiting a body mass index $<25$ or $\geq 25$ (10/10). Similarly, there were 10 smoking individuals 
with PASH, 2 former smokers, and 7 declared nonsmokers. Familial occurrence of the syndrome was reported in one-fourth of the cases. The most common genetic abnormalities were an increased number of microsatellite repeats (CCTG $\geq 5$ ) in the proline-serine-threonine phosphatase-interacting protein 1 (PSTPIP1) promoter region reported in $15 \%$ of the patients, alterations in the coding region of the PSTPIP1 gene in 3 cases, and $\gamma$-secretase complex gene mutations (nicastrin) in 5 cases. Two of the nicastrin mutation-affected individuals were nonobese nonsmokers in Hurley stage III, and three belonged to an Iranian family, whose 24 members demonstrated various combinations of PG, HS, and acne [3133].

Regarding the Hurley classification for sporadic HS patients, stage I was the most common one, whereas only $4 \%$ of patients were reported as stage III with diffuse or near-diffuse involvement [34]. On the contrary, most cases diagnosed with PASH (62\%) were assessed to have extended disease (Hurley stage $\geq \mathrm{II}$ ), and among them Hurley stage III was detected in approximately half of the patients $(n=13)$.

The severity of clinical presentation also concerns acne: 22 (56\%) of PASH patients had severe forms of the disease, such as acne nodulocystica, acne fulminans, or acne conglobata. Acne was the most common first manifestation of PASH (36\%), typically followed by HS and finally PG. Interestingly, although by definition PASH lacks arthritis, in three articles PASH either coexisted or was preceded by joint symptoms. An example of PASH/ SAPHO overlap was given in the paper by Marzano et al. [35], in which 1 patient was described to have coxitis in early childhood. PASH coexisting with rheumatoid arthritis was identified [36, 37].

\section{Discussion}

The characteristics of patients with PASH syndrome persist, in contrast to patients with sporadic, nonsyndromic HS. In a case series by Hsiao et al. [38], 10 out of 11 patients presenting with HS and concomitant PG were female.

When encountering patients with severe acne and HS, awareness should be raised towards the possible coexistence of PG. The temporal sequence is in accordance with available studies on concomitant HS and PG; Hsiao et al. [38] demonstrated that PG always occurs after HS, and the median time interval varied between 2.5 [38] and 21 [39] years, suggesting that PG could be a late-onset manifestation of the same defect that causes autoinflammation in HS. PG itself can be associated with multiple oth- er comorbidities, including arthritis, IBD, HS, and acne conglobata [40]. The cause of PASH syndrome remains currently unknown. In most cases no provoking factor was identified, apart from bowel bypass surgery for obesity [41] and colectomy for UC [42], suggesting an aberrant nonspecific immune response to bacterial antigens. The available data regarding potential environmental factors are scarce. In contrast to pyogenic arthritis-pyoderma gangrenosum-acne (PAPA) syndrome, no definite genetic background has been proven for PASH. Candidate genes can be divided into two groups: a $\gamma$-secretase complex family gene and genes whose role has been previously highlighted in other autoinflammatory diseases, such as PSTPIP1.

The increased number of microsatellite CCTG repeats in the PSTPIP1 promoter region had previously been observed in patients with "aseptic abscess syndrome," in which IBD is a common comorbidity (66\%) [43]. In a current study, PSTPIP1 promoter disturbances were harbored exclusively by PASH patients [32]. Mutations in the coding region of the PSTPIP1 gene occur more rarely [44-47]: the p.R405C variation was demonstrated in a patient with aggressive $P G$ and could be pathogenic $[46,48]$. In the study by Duchatelet et al. [32], HS and acne cosegregated in three generations. It was hypothesized that a maternal PSTPIP1 mutation could be responsible for acne and HS, while a second mutation might cause PG. An aberrant variant of PSTPIP1 increases pyrin binding and IL- $1 \beta$ production and leads to a migratory phenotype in phagocytes $[10,46,49]$. Co-occurrence of mutations in NOD2 and LPIN2 was reported in SAPHO syndrome [14, 50].

The second genetic region in focus, $\gamma$-secretase, encodes an endoprotease complex that catalyzes the cleavage of certain transmembrane proteins, such as amyloid precursor, E- and N-cadherin, and Notch receptors [33]. One of the $\gamma$-secretase subunits is nicastrin [32, 51-53].

Judging by the heterogeneity of clinical and genetic presentations, PASH may present as just one possible phenotype of a still undefined autoinflammatory condition, with incomplete gene penetrance and expression $[32,54]$. Low-penetrance variants or a polygenic distribution might contribute to the underestimation of the contribution of genetics in syndromic HS. 
PAPASH, PsAPASH, PASS, and Beyond: Joint Involvement as a Common Feature of HS-Related Autoinflammatory Syndromes - the Concept of the "Autoinflammatory March"

\section{Results}

Eight cases of PASS, 6 cases of PAPASH, and 3 cases of PsAPASH syndrome were retrieved. The 6 PAPASH patients had a mean age of 33.5 years at the time of diagnosis, which is similar to the mean age of PASH cases detected. PASS patients were slightly younger (26 years). The 3 cases of PsAPASH identified so far were aged 22, 50 , and 55 years. As far as each organ involvement is concerned, we identified arthritis in 35\% of patients with PASH, PAPASH, PsAPASH, and PASS. Two patients developed UC (PAPASH and PASH) and one developed $\mathrm{CD}$ as a second or third consecutive manifestation of syndromic HS. In $53 \%$ of the detected cases with PAPASH, PsAPASH, and PASS, cutaneous manifestations usually preceded other organ involvement.

We also detected an additional number of reports describing HS patients with two concomitant autoinflammatory conditions, but the diagnosis of a specific syndrome was not stated. The mean age of these HS patients without a defined syndrome was 36.6 years. Case reports included mouth and genital [55] or even corneal ulcerations [56], resembling a variation of PG. Sixty percent suffered from concomitant arthritis, while 6 patients developed $\mathrm{CD}$. Cutaneous preceding symptoms were reported in $33 \%$ of cases.

\section{Discussion}

Syndromic HS could be more frequent than expected. The earliest report from the 1980s described a patient with concomitant HS, Adamantiades-Behçet disease and arthritis [55]. In a case series of 11 patients with coexisting HS and PG, 3 patients fulfilled the criteria of PASH before the acronym PASH was established [38].

The mean age of described cases is higher than the mean age of patients with sporadic disease, possibly reflecting an even higher diagnostic delay. "Adding" further symptoms to HS results in the more complex phenotypes of PAPASH, PASS, and PsAPASH syndromes (Table 1). A typical sequence was acne vulgaris/HS followed by PG and subsequently musculoskeletal/gastrointestinal symptoms, constituting an "autoinflammatory march."

PASS, PAPASH, and PsAPASH can be distinguished by different type of joint involvement, namely ankylosing spondylitis for PASS [57] and pyogenic arthritis for
PAPASH [47], while PsAPASH is a PAPASH variant with concomitant psoriatic arthritis [58].

Overall, the prevalence of arthritis occurs within onethird to two-thirds of PASH, PAPASH, PsAPASH, PASS, and uncategorized syndromic HS patients. In the largest cohort with joint involvement reported by Gottlieb et al. [59], 9 patients with HS (2 PAPASH, 1 PsAPASH, 6 PASS) and joint disease were described. HS was the initial entity in 6 patients. A multicenter, observational study on a population of $640 \mathrm{HS}$ patients established a frequency of musculoskeletal symptoms of $29 \%$ [60]. Axial and peripheral arthropathy correlated with HS and acne conglobata is usually a reactive arthritis manifesting over the age of 22 years [60,61]. The onset of arthritis tends to be insidious, 2-15 years after the onset of skin lesions, asymmetric and correlated with HS severity [62]. Arthritis observed as a comorbidity of HS shares certain common features with spondyloarthropathies but is not linked to the HLA-B27 histocompatibility antigen [62, 63].

The less frequent concomitant manifestation concerned IBD, although the latter is a bystander in HS diagnosis [13]. Twenty-three percent of 255 IBD patients were also diagnosed with HS, with IBD manifesting on average 4 years before HS [64]. In another study, the frequency of HS in 1,260 patients with IBD was estimated at $7-11$ vs. $1-2 \%$ in the general population [65]. Interestingly, the activity in the two organ systems is not linked [66].

Eye involvement in syndromic HS was sporadically reported: 6 patients, without a defined diagnosis for their syndrome, presented ocular signs. In 3 cases concomitant Adamantiades-Behçet disease could account for anterior uveitis or episcleritis; 2 patients suffered from conjunctivitis and 1 patient had bilateral ulcerative keratitis (Mooren's ulcer) $[55,56,62]$. In a study by Saygin et al. [67], the most common types of inflammatory eye involvement were uveitis (65\%) followed by scleritis (30\%) and peripheral ulcerative keratitis.

These data suggest a common autoinflammatory pathophysiologic mechanism for cutaneous, joint, gastrointestinal, and ophthalmic manifestations. Thus, HS in combination with symptoms such as ocular pain, redness, or decreased vision requires not only a prompt referral to an ophthalmologist, but also diagnostic procedures for multiorgan involvement. 


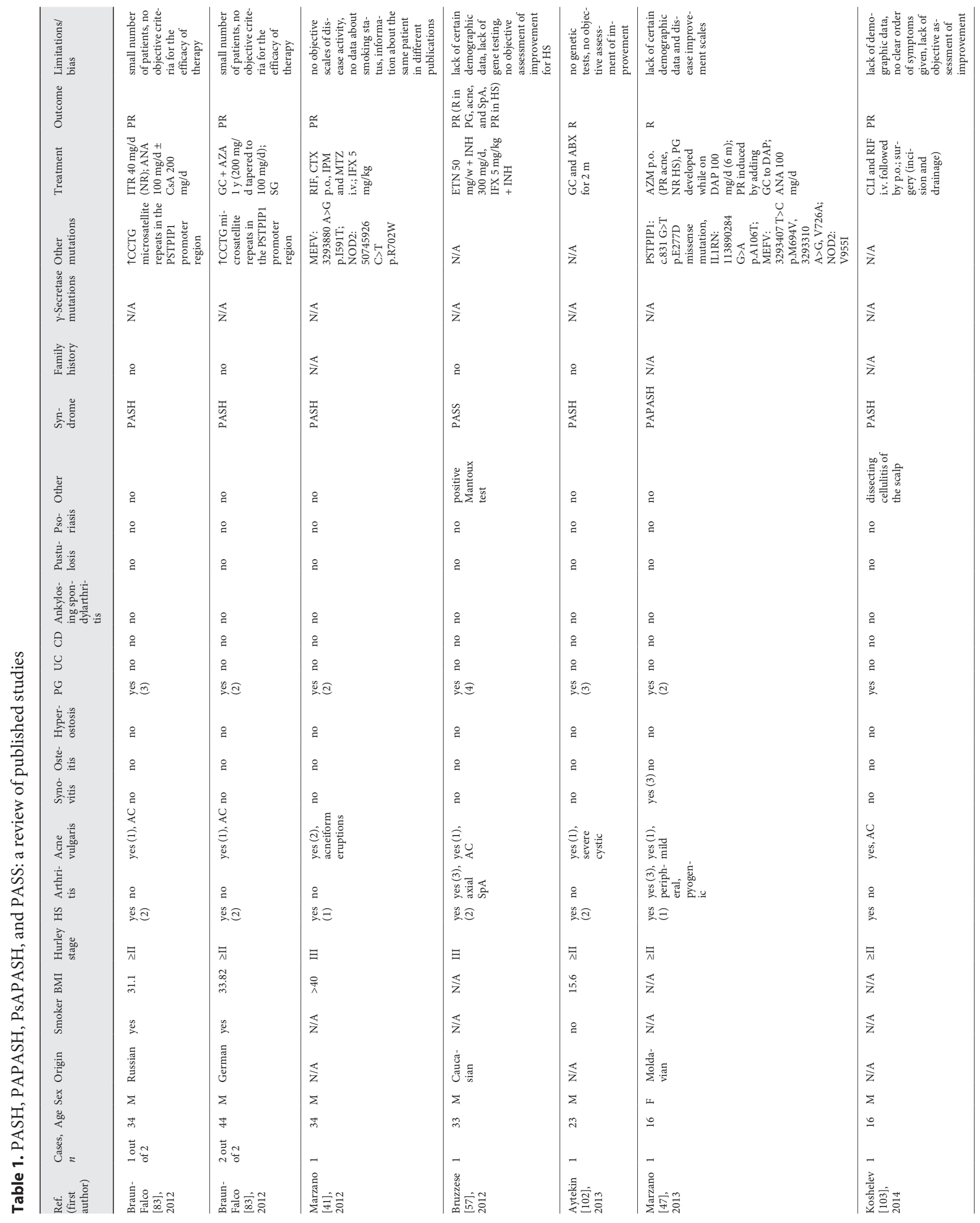




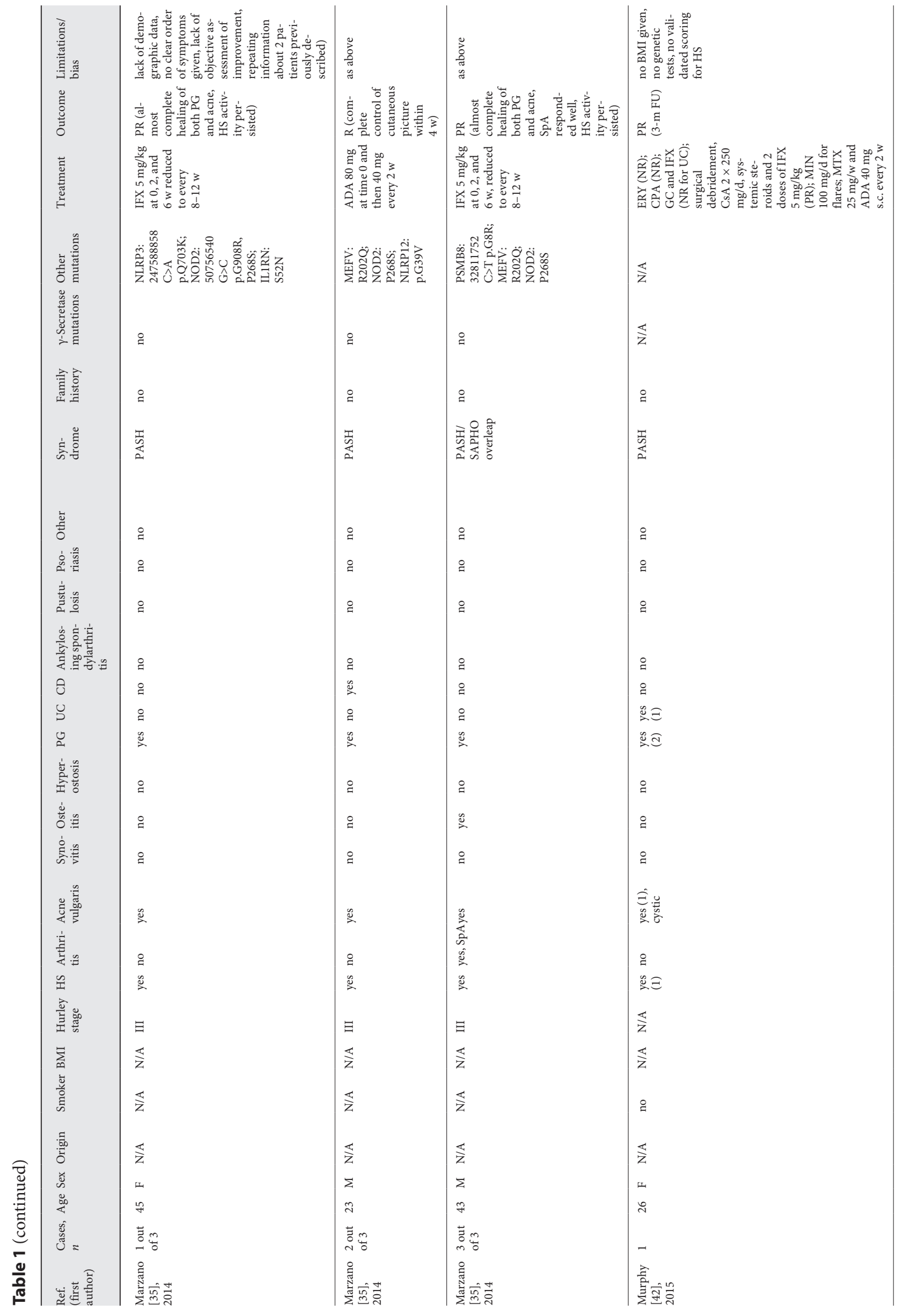




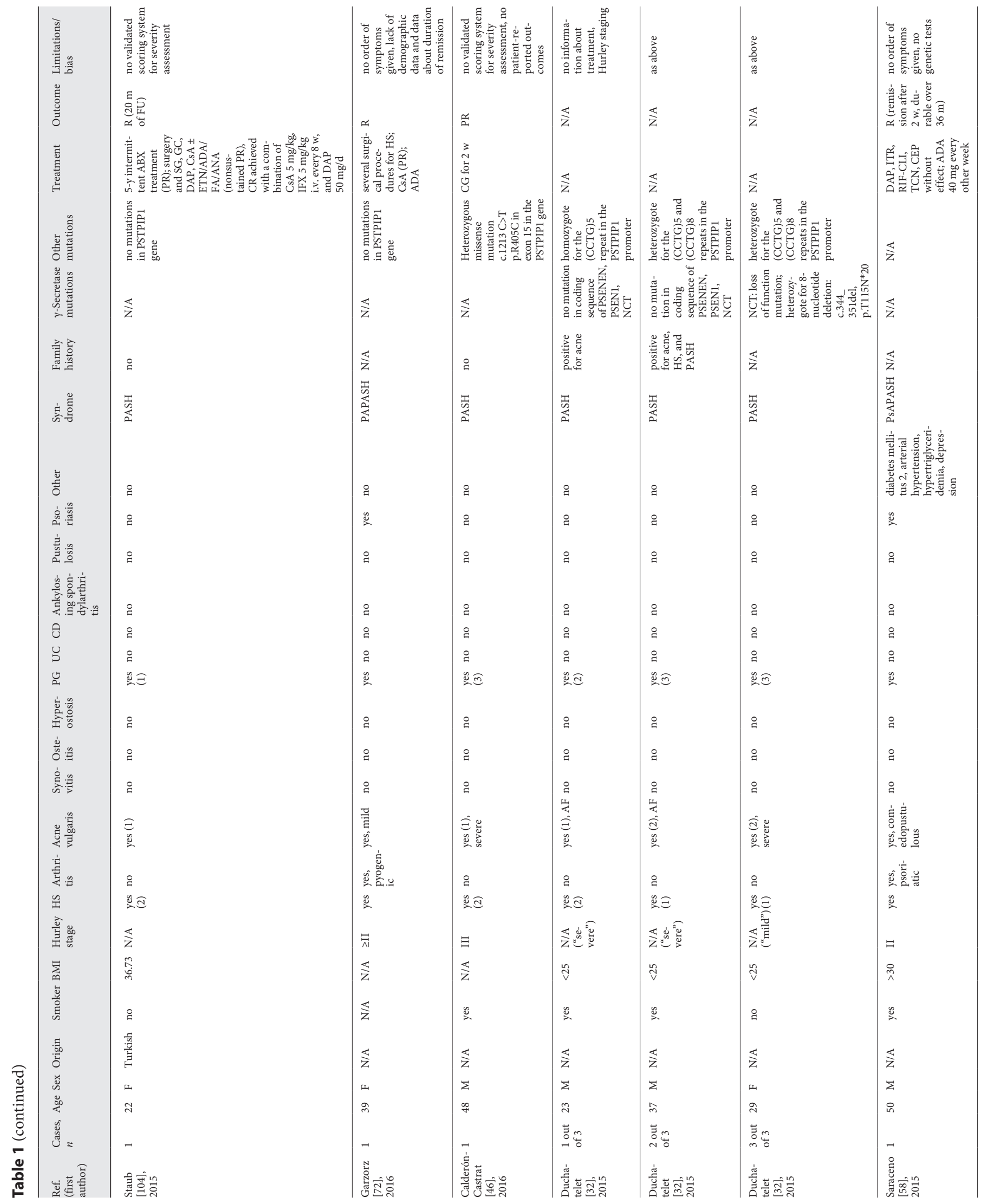




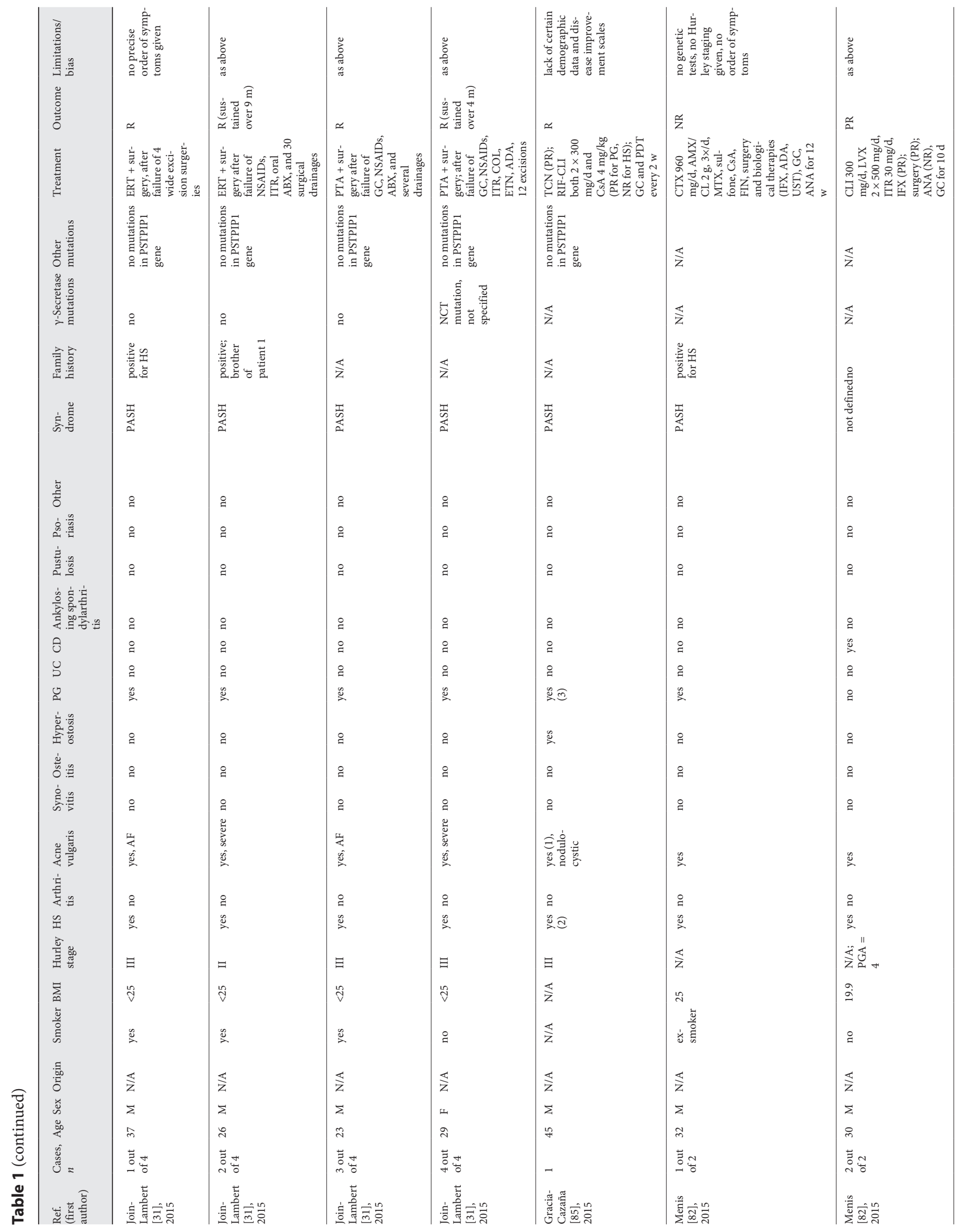




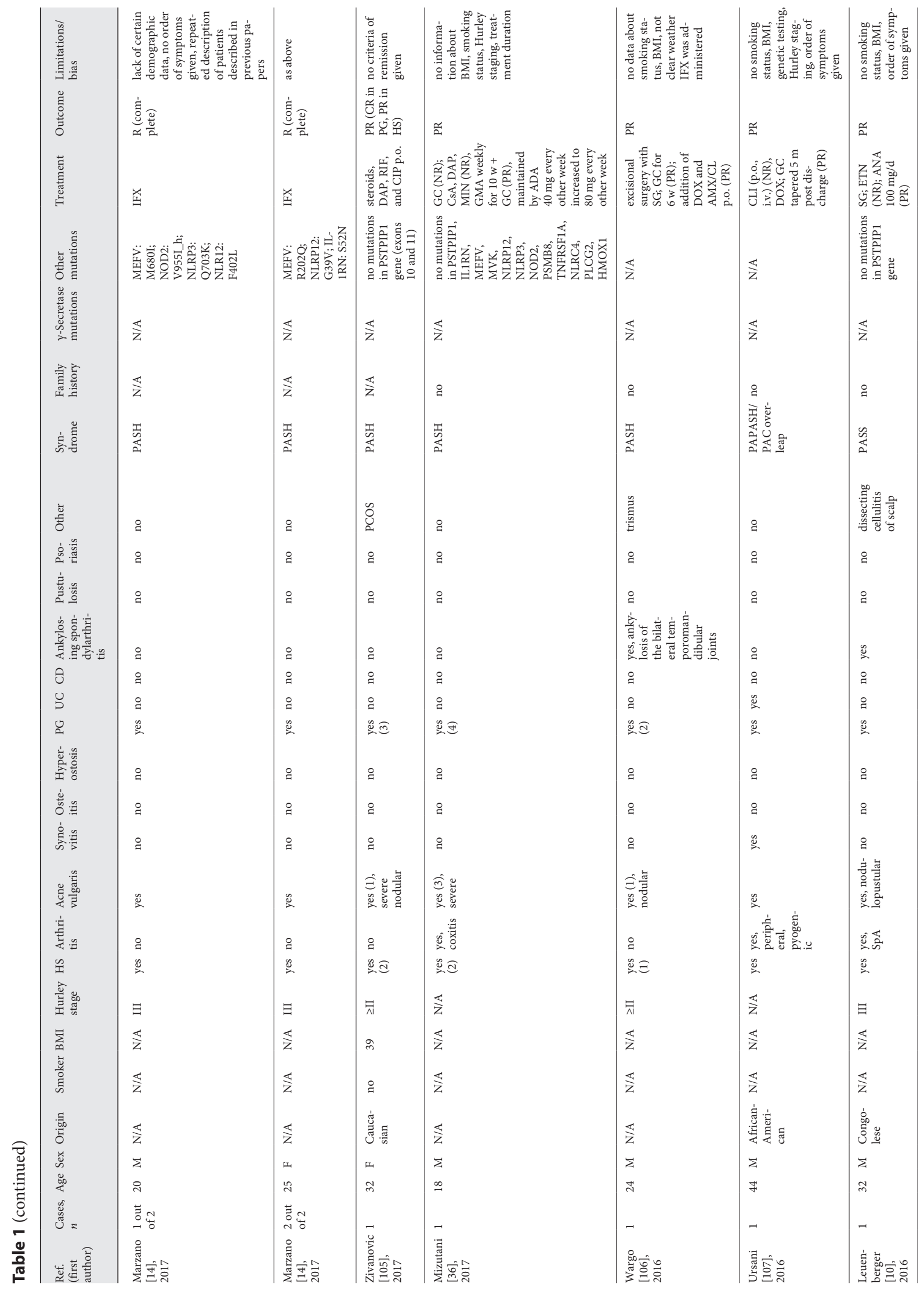




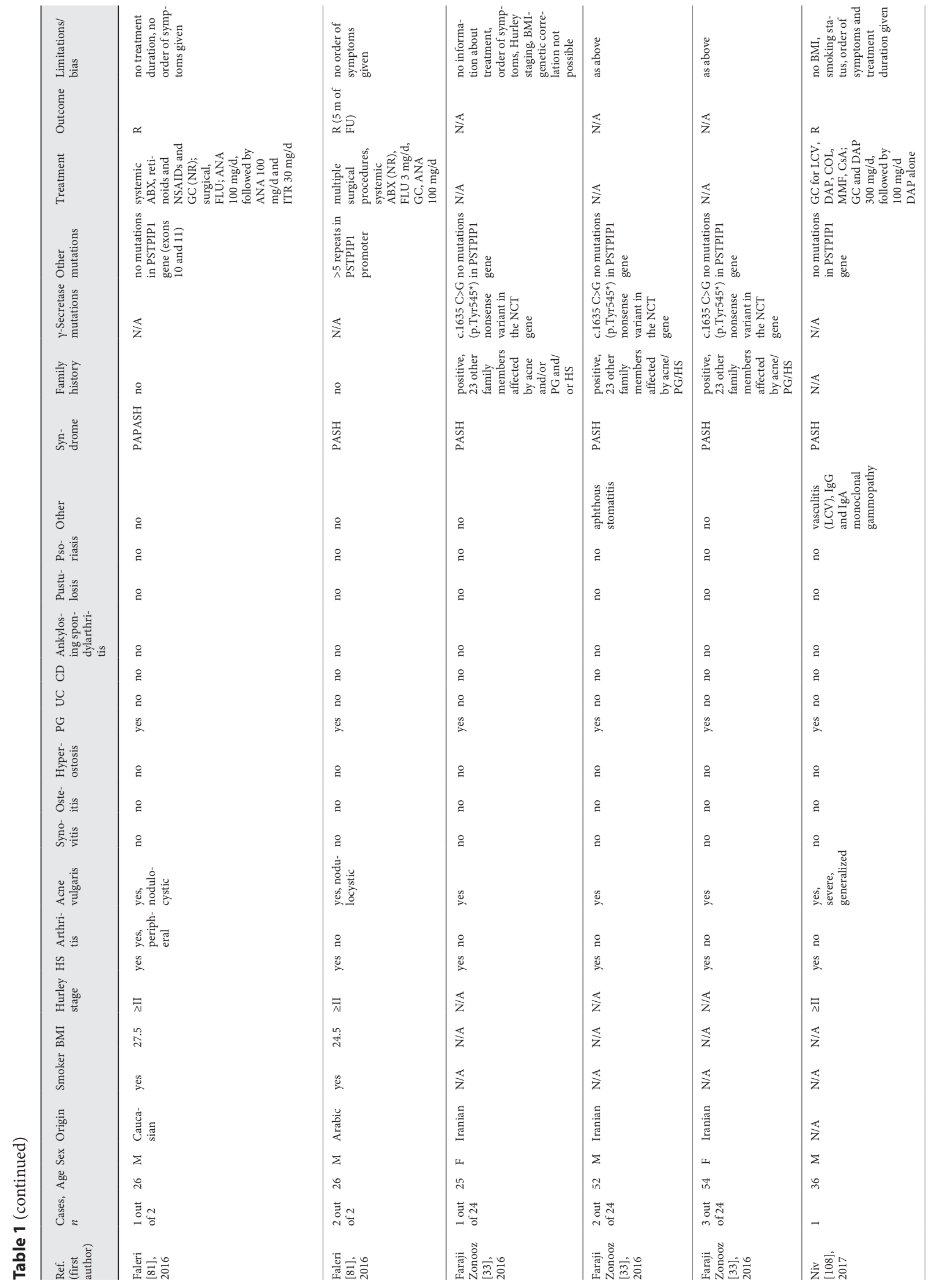




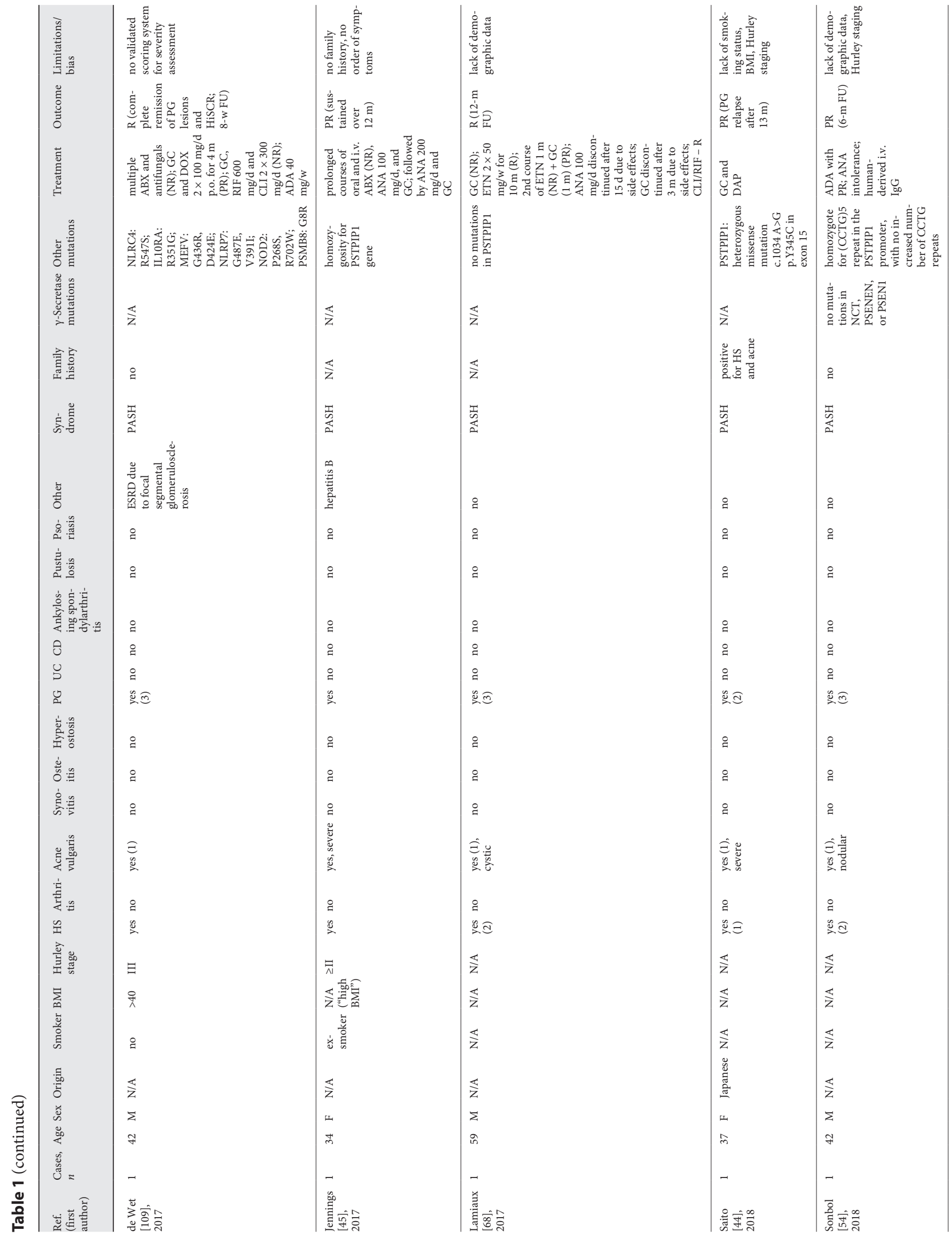




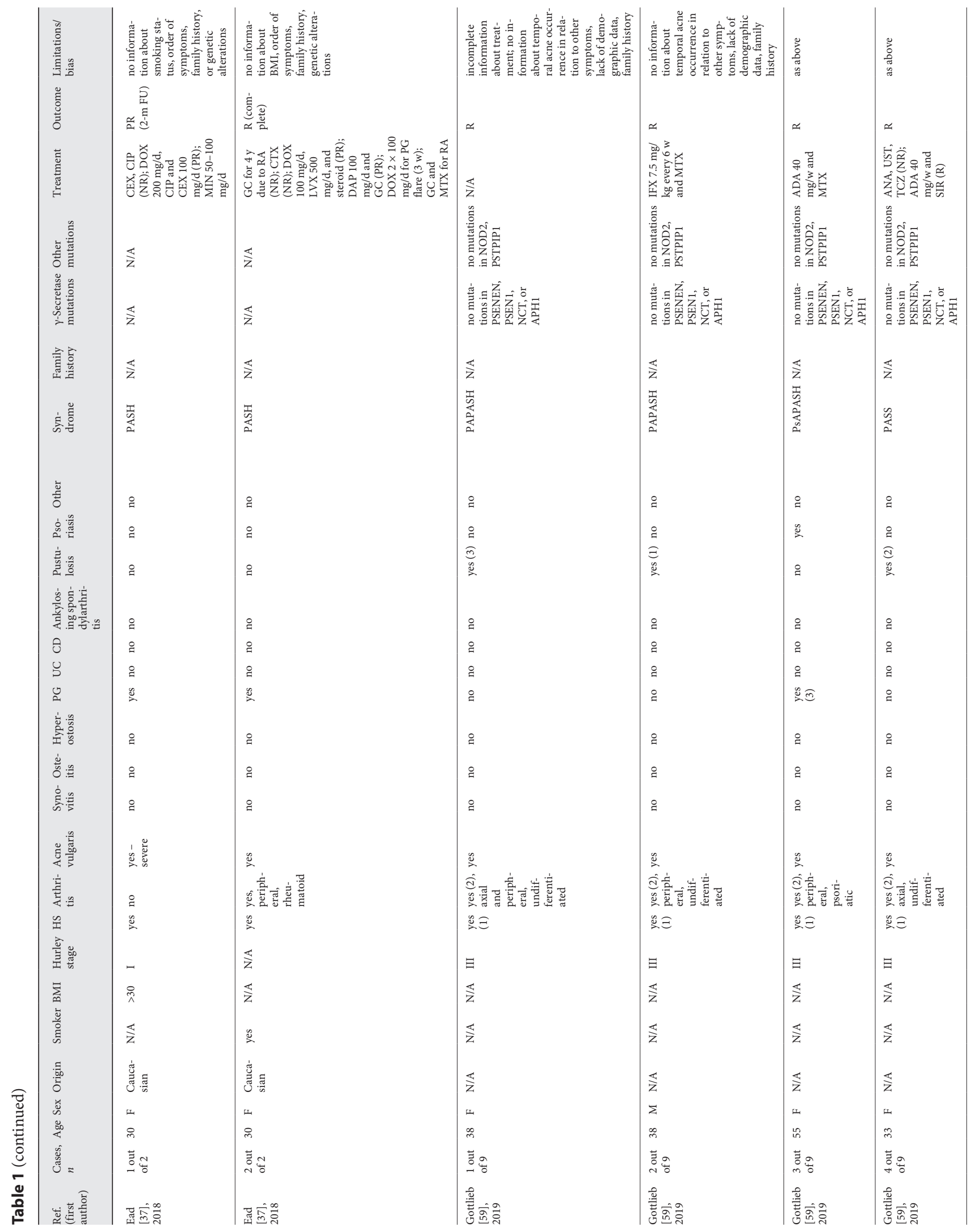




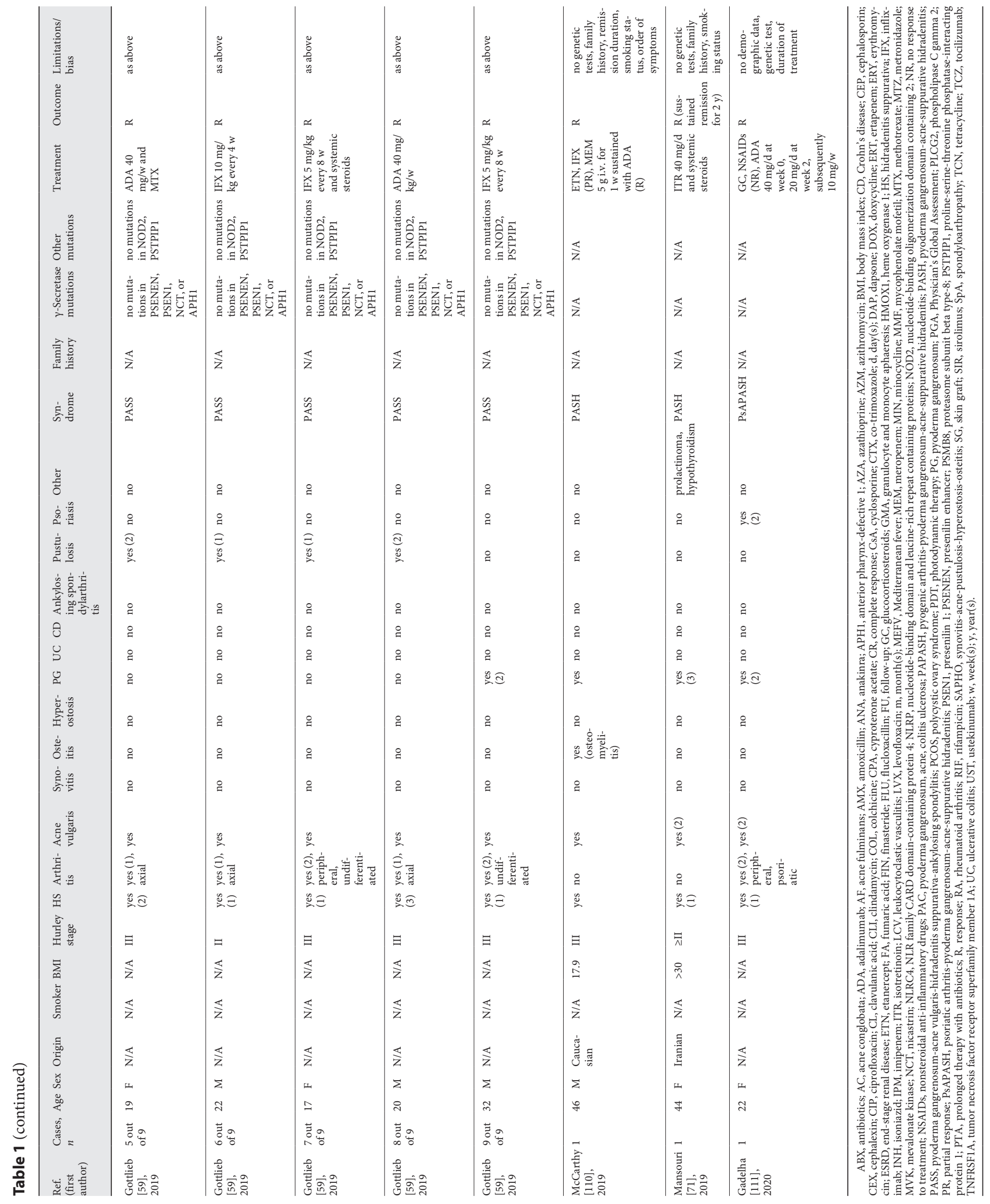




\section{Therapy of PASH, PAPASH, PsAPASH, and PASS}

\section{Results and Discussion}

Due to the many common clinical features, suspected common pathogenesis, and therapeutic options shared between PASH, PAPASH, PsAPASH, and PASS and undefined syndromic HS, these syndromes are presented and discussed here collectively (for details see Tables 1, 2 ). The therapy of syndromic HS sets a challenge as the medication should be ideally simultaneously effective towards all signs of the syndrome.

In the analyzed patient cohort, implemented drugs were systemic antibiotics, isotretinoin, classic immunosuppressive agents, and biologics with/without surgery for HS. Why some patients remain resistant to multiple biologics while others are successfully treated solely with antibiotics and systemic steroids remains unclear. In single cases HS was the most refractory entity. Clinical response documentation was subjective, not based on validated disease outcome measures (HiSCR, IHS4) or widely accepted patient-reported outcomes, which limits the quality of the conclusions. The severity of a specific organ manifestation and the medical specialty, which gets confronted with the treatment first, usually defines the orientation of the treatment of choice, with only certain aspects of the syndrome treated effectively.

Antibiotics remain a widely implemented treatment modality. Attempts with tetracyclines were registered in $17 \%$ of patients, however $67 \%$ exhibited partial or no response. Tetracyclines were most frequently prescribed, followed by clindamycin/rifampicin and dapsone. The known anti-inflammatory properties of certain antibiotics can account for their frequent use [68]. A promising option may be prolonged targeted antibiotic therapy using antibiotics based on microbiological culture. Four severe PASH patients achieved clinical remission with ceftriaxone and oral metronidazole or intravenous ertapenem [31]. Despite bacteria often being seen as bystanders in HS pathogenesis $[69,70]$, the authors postulated that treatment was effective primarily due to their antimicrobial and not to their anti-inflammatory properties [31].

Oral retinoids did not result in favorable effects in the majority of the reported cases (80\%). In a single PASH case, isotretinoin in combination with oral steroids induced a 2-year remission [71].

Among the classic immunosuppressants, cyclosporine (14\% of patients) and methotrexate (MTX) (7\% of patients) were the most frequently reported treatments, and the patients who responded to them were 7 out of 12 and 4 out of 6 , respectively. Both drugs were used as mono-

Syndromic Hidradenitis Suppurativa and multitherapy, in the latter case particularly in combination with biologics (adalimumab, infliximab) [59]. Tapering of cyclosporine was connected to relapses [72].

The most commonly used biologic agents were infliximab and adalimumab (17 cases each), followed by anakinra (13 cases). Dinarello [16] suggested that, in contrast to autoimmune diseases, TNF $\alpha$ antagonists in autoinflammatory syndromes do not produce favorable outcomes and can even exacerbate symptoms. According to the authors, IL- $1 \beta$ blockade brings more benefit. The reason why some subjects respond to anti-IL-1 agents and some to anti-TNFa is yet to be elucidated.

TNFa inhibitors might constitute the most effective treatment modality for syndromic HS. Eighty percent of patients treated with infliximab and adalimumab showed some degree of clinical response: very good response was noted in $47 / 59 \%$ and partial response in $41 / 24 \%$ of patients treated with infliximab/adalimumab, respectively. Single patients were resistant to treatment, with HS being the most resistant component; PG, acne, and spondyloarthropathy responded well [73].

Infliximab is approved for inflammatory syndromes such as $\mathrm{CD}$, rheumatoid arthritis, psoriasis, Adamantiades-Behçet disease, and PG [66], with its effectiveness demonstrated in randomized clinical trials. Fifty percent of 38 patients with moderate to severe HS showed partial response after 8 weeks in comparison to placebo [74]. In a case series of 30 patients with PG, the total response and complete remission rate were 69 and $21 \%$, respectively [75]. When infliximab was first used for HS in the setting of CD, both of them improved [76, 77].

Adalimumab, a human monoclonal IgG1 antibody specific for TNFa, is the only biologic approved for the treatment of HS $[78,79]$. PAPASH treated with adalimumab resulted in IL-17 and IL-22 increases in serum. Taking into account the aforementioned TNFa/IL-17 synergy, a combination therapy with a biospecific antiTNFa/IL-17 antibody would constitute a promising option [72].

Finally, use of the IL-1 inhibitor anakinra has been reported in the treatment of PASH syndrome [81]. Three out of 7 patients responded to treatment with $100 \mathrm{mg}$ anakinra/day, developing a substantial but not complete response, while in 4 patients therapeutic failure with intolerable side effects was documented $[82,83]$. Moreover, anakinra was used in 2 PAPASH patients, providing good control of the disease $[47,81]$. In one of the reported PASS cases, anakinra was proven ineffective [59]. In contrast, in an open-label pilot study with 6 HS patients, excellent results with anakinra were shown [84]. No com- 


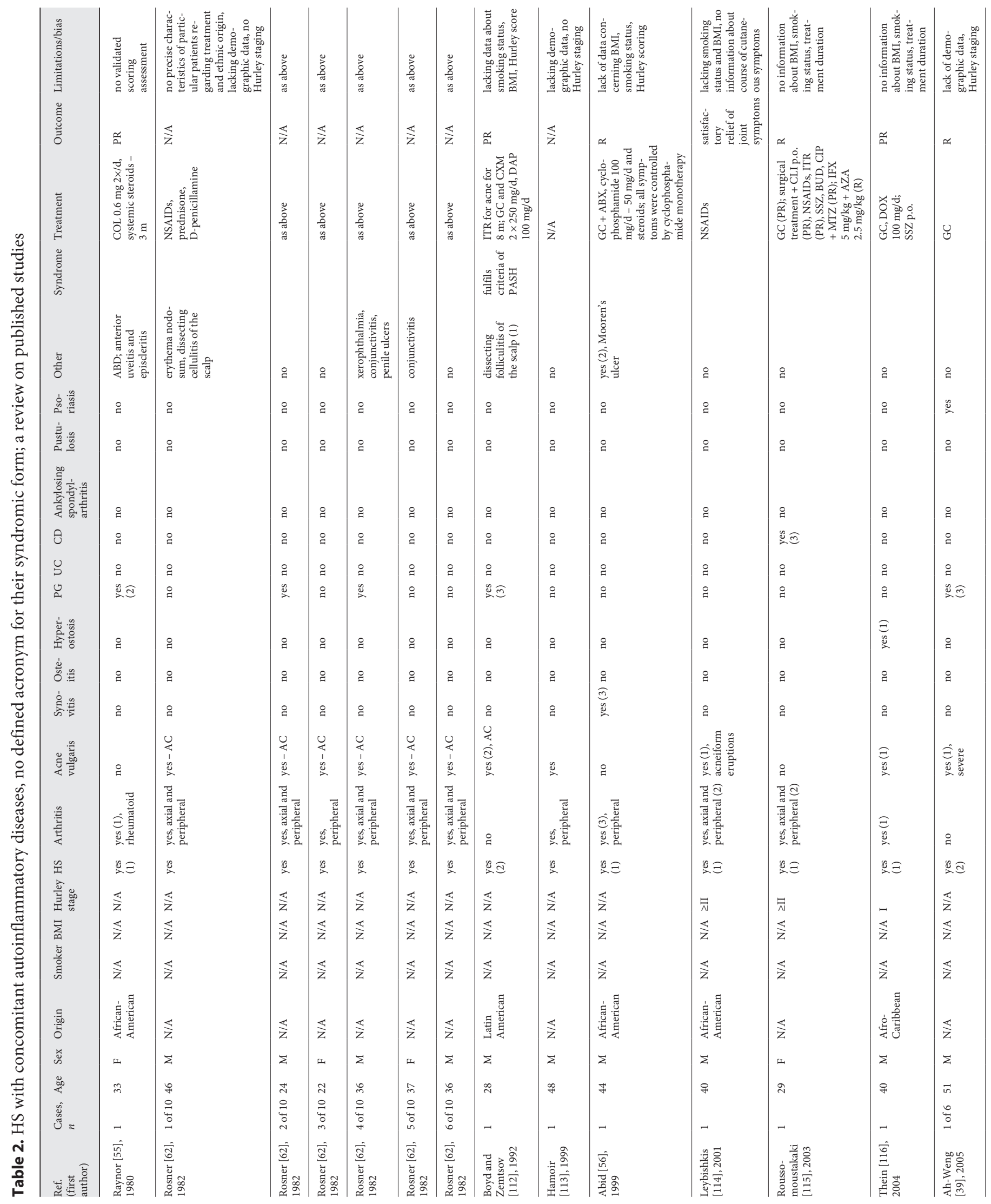




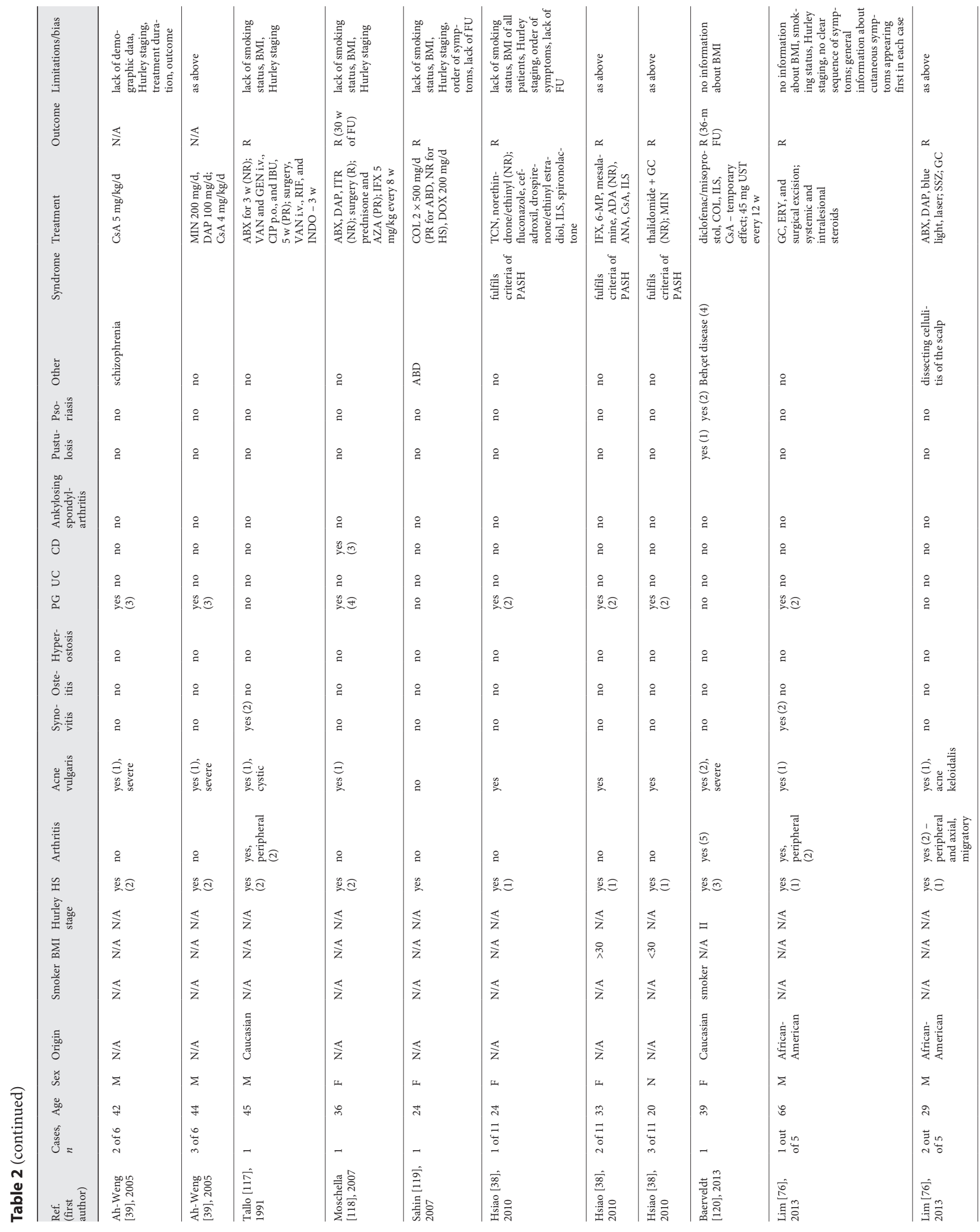




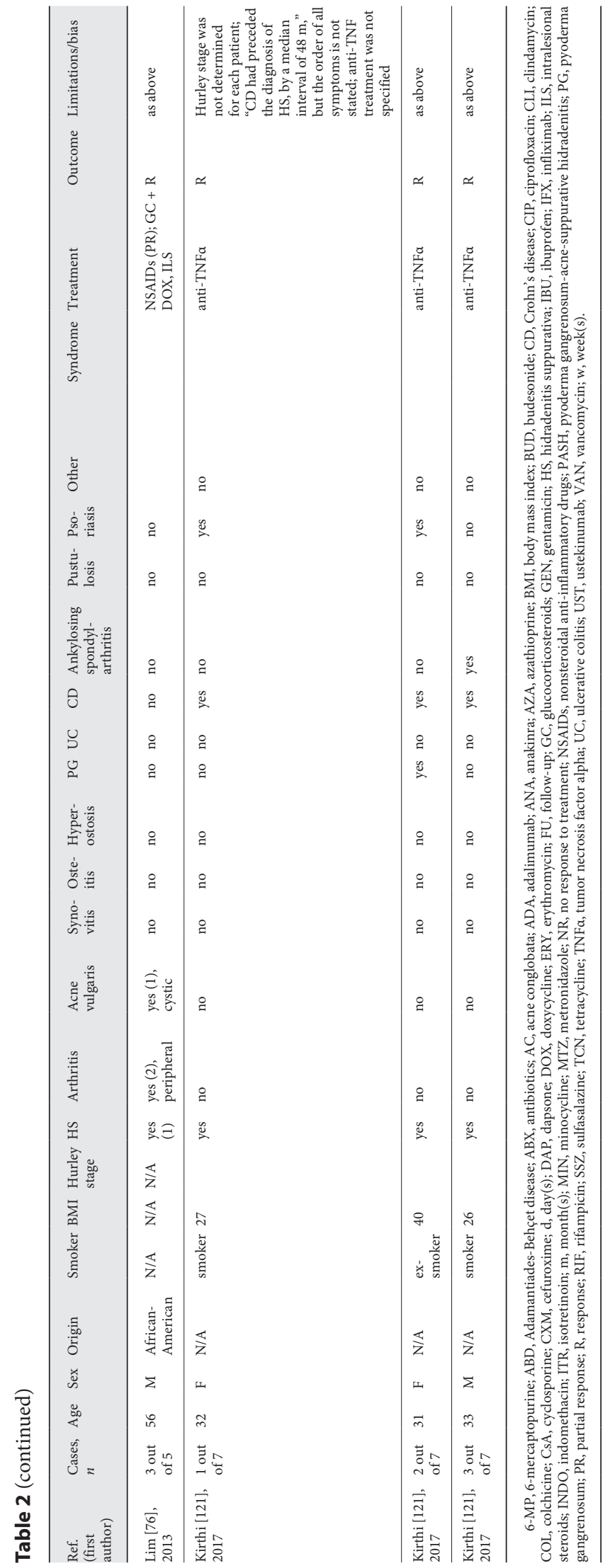

plete remission of symptoms in syndromic HS was noted while on anakinra monotherapy, suggesting its ranking as a biologic of second choice when TNFa inhibitors are ineffective or contraindicated.

There are single reports describing the use of other biologics, such as etanercept ( 6 cases), ustekinumab (3 cases), or tocilizumab (1 case), mostly with limited effects [59]. Taking into account the complexity of syndromic HS, a combination of biologic agents with two other medications such as classic immunosuppressive drugs, steroids, and/or antibiotics might be a viable therapeutic option (Table 1). Rarer and more complex methods to reduce the inflammatory load of such patients, such as granulocyte and monocyte adsorption apheresis [36], photodynamic therapy, and intravenous immunoglobulins have also been reported $[54,85]$.

\section{SAPHO Syndrome and Syndromic HS: An Underestimated Comorbidity?}

\section{Results}

We managed to retrieve 10 case reports and a case series with SAPHO-related HS (Table 3). This included 21 patients, with a female:male ratio of 1:1.2 and a mean age of 38.7 years. The origins of the patients are only scarcely documented. Only 5 were reported as smokers, while extensive documentation on weight or body mass index was lacking. The order of organ or system involvement was described in only $13 / 21$ cases. We observed that in $61 \%$ of the documented cases, HS preceded the osteoarticular symptoms, either alone or in combination with acne vulgaris or acne fulminans (Table 3 ).

\section{Discussion}

SAPHO syndrome as a term entails the association of cutaneous manifestations, namely palmoplantar pustulosis or pustular psoriasis, severe acne (fulminans or conglobata) and HS, with certain osteoarticular manifestations. Since dermatologists did not participate in all reports, HS was omitted from the most common acronym [86]. Osteoarticular symptoms can occur without affecting the absence or presence of cutaneous involvement. Still, dermatologic manifestations, among which HS is also included, very often precede bone lesions and might be forgotten until their development. The lesions can also develop long after the osteoarticular lesions. Our search underlined that HS, alone or together with acne, is mostly an initial symptom is such cases and might prophesize SAPHO [87]. The male predominance of SAPHO with 


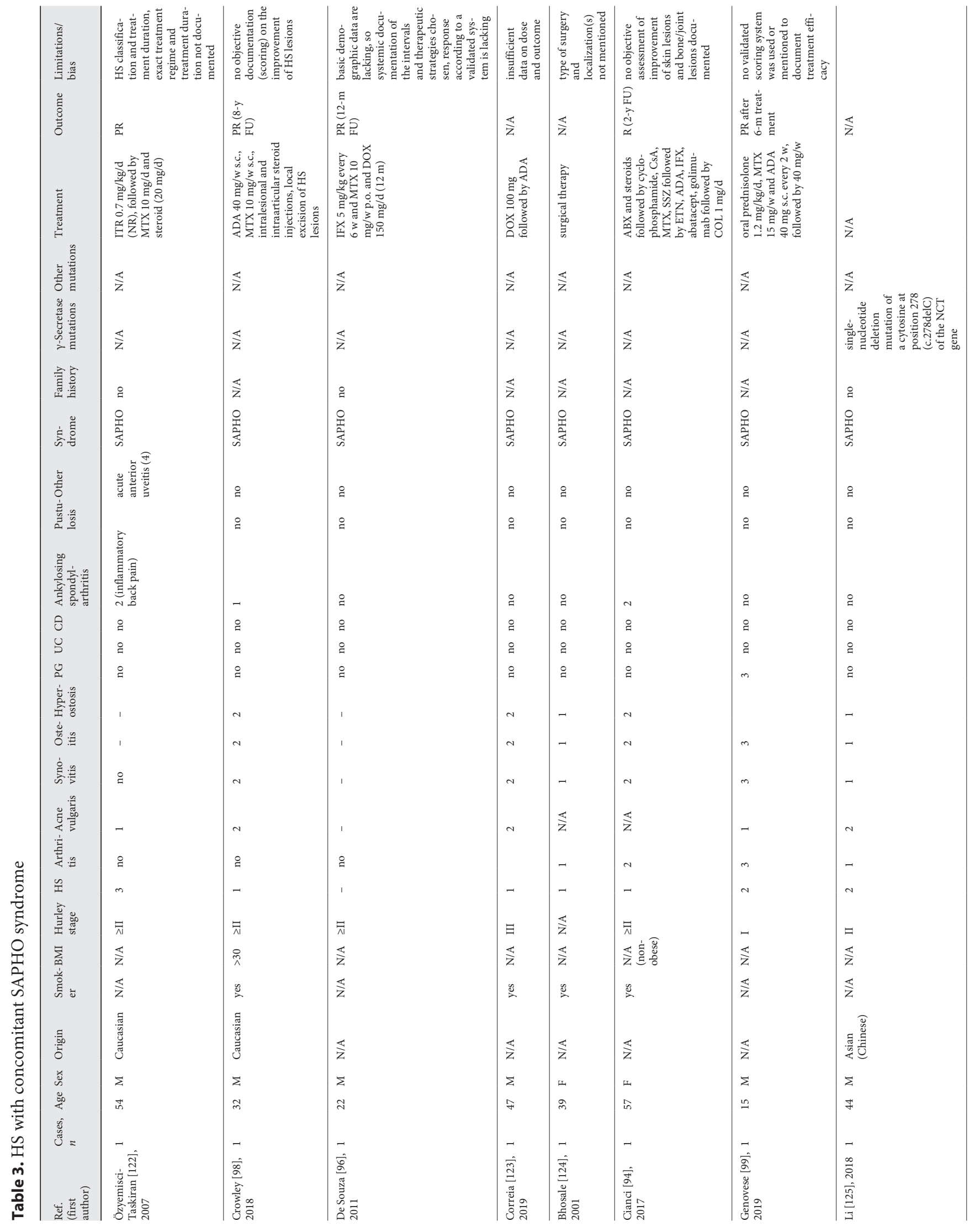




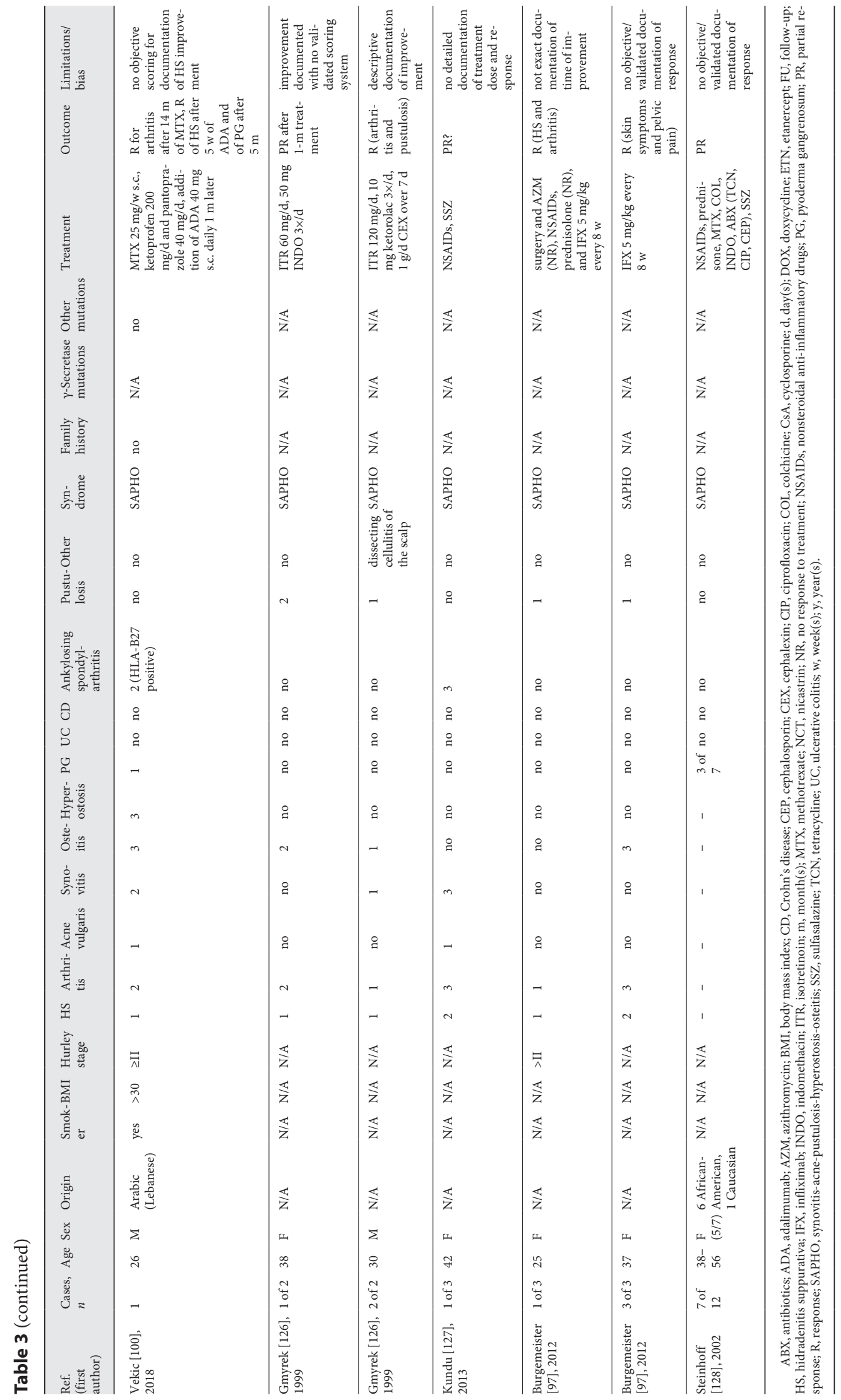


HS was not confirmed in this study [87]. Palmoplantar pustulosis is considered the most common dermatologic manifestation (50-75\%), affecting $60 \%$ of patients with extensive follow-up $[88,89]$.

The osteoarticular involvement has an insidious onset but can manifest with debilitating pain, which is exacerbated by movement or pressure. In adults, the axial skeleton is most commonly involved, with the anterior chest wall primarily and the spine secondarily being the most commonly affected skeletal sites [90]. Bone scan reveals the pathognomonic "bull's head sign" of the sternocostoclavicular region, with the manubrium sterni representing the skull and the inflamed sternoclavicular joint and the adjacent claviculae representing the horns. Interestingly, the affected joint could remain clinically "silent" [91]. Conventional magnetic resonance imaging is more sensitive and computed radiography is also well suited for detailed imaging of the sternoclavicular region. Sacroiliitis can be seen in up to $52 \%$ of SAPHO patients. Hyperostosis and osteitis are chronic inflammatory reactions involving the cortical and medullary bone. Early lesions appear usually osteolytic, followed by mixed lytic/sclerotic lesions with disease progression and cortical thickening at the end stages of the disease [92]. The criteria of Benhamou et al. [93] are used for the diagnosis of the syndrome [86].

\section{Therapy of HS-Related SAPHO Syndrome}

\section{Results and Discussion}

The therapeutic options for the 21 cases are summarized in Table 3. In brief, the order of organ involvement was usually dictated by the first specialty that encountered and thus treated the syndrome. Osteoarticular symptoms were treated with nonsteroidal anti-inflammatory drugs, sulfasalazine and MTX, while cutaneous symptoms were treated with antibiotics, such as tetracyclines, ciprofloxacin, and cephalosporins. Isotretinoin, cyclophosphamide, and cyclosporine achieved only partial remission of the lesions. In most cases, anti-TNFa treatment (infliximab, adalimumab, golimumab) had to be initiated with initial good control of both cutaneous and osteoarticular symptoms. In many recalcitrant cases, anti-TNFa treatment had to be combined with MTX, prednisolone, or tetracyclines alone or in combination with HS surgery to better control the HS symptoms. In recalcitrant osteoarticular manifestations, intraarticular steroid injections were necessary. In one case almost full remission was reported with colchicine $1 \mathrm{mg}$ /day after a 2-year follow-up [94].

Syndromic Hidradenitis Suppurativa
As previously mentioned, most therapeutic modalities are based on case series, case reports, and expert judgement. Nonsteroidal anti-inflammatory drugs are a first-line symptomatic treatment, reported to show insufficient pain relief during flares in $50 \%$ of patients [86, 89]. Intraarticular corticosteroids are effective for patients with refractory osteoarticular symptoms $[87,88]$. The use of steroid-sparing agents in refractory cases, including MTX, sulfasalazine, or azathioprine, was only reported as beneficial for noncutaneous symptoms [88, 95]. Anti-TNFa agents were ultimately used in refractory cases, including infliximab [94, 96, 97], etanercept [94], or adalimumab [80, 94, 98-100]. The response was usually rapid for both cutaneous and osteoarticular symptoms. However, shortening of the intervals or dose intensification was individually required. A recent review of 66 SAPHO cases identified anti-TNFa treatment as first choice after nonresponse to conventional treatment, while skin disease (57\%) exhibited a more common response than osteoarticular symptoms (38\%). In contrast, anti-IL-1 treatment was proven beneficial for musculoskeletal symptoms but not for cutaneous symptoms [101].

\section{Conclusion}

The co-occurrence of multiple autoinflammatory signs in patients with HS is clearly neither seen as a common comorbidity nor as an accidental association. Our report reviews systematic autoinflammatory clinical signs connected with HS, not only through collecting cases of established syndromes, but also through combination of HS with two other inflammatory diseases, which may constitute novel syndromic manifestations. The "autoinflammatory march" emphasizes the key role of dermatologists to remain alert for signs of systemic involvement when encountering a patient with severe HS/acne. The limitation of this review is the lack of large-scale studies on the topic. Validated scoring systems for both cutaneous and osteoarticular symptoms can increase the quality of evidence and provide the necessary tools for a guideline or interdisciplinary expert consensus for the treatment of such patients.

\section{Key Message}

Early diagnosis of HS is pivotal to prevent the irreversible consequences of autoinflammatory march. 


\section{Statement of Ethics}

This report was written in accordance with the Preferred Reporting Items for Systematic Reviews and Meta-Analyses (PRISMA) and the MOOSE proposal, where applicable.

\section{Conflict of Interest Statement}

C.C. Zouboulis has received thematically relevant honoraria from AbbVie, Incyte, Indorsia, Inflarx, Janssen, Novartis, Regeneron, and UCB as advisor, which had no influence on the preparation of the manuscript. His departments have received grants from AbbVie, Inflarx, Novartis, and UCB for his participation as investigator. All other authors have no conflicts of interest to disclose.

\section{Funding Sources}

This research did not receive any funding.

\section{Author Contributions}

G. Nikolakis and K.P. Kaleta performed the research and wrote and critically reviewed the manuscript. A.G. Vaiopoulos and C.C. Zouboulis contributed to the study design and critically reviewed the manuscript. K. Wolter participated in the preliminary research. S. Baroud and A. Wojas-Pelc contributed to the revision of the manuscript and designed some of the tables.

\section{References}

1 Kurzen H, Kurokawa I, Jemec GB, Emtestam L, Sellheyer K, Giamarellos-Bourboulis EJ, et al. What causes hidradenitis suppurativa? Exp Dermatol. 2008 May;17(5):455-6.

2 Zouboulis CC, Tzellos T, Kyrgidis A, Jemec GB, Bechara FG, Giamarellos-Bourboulis EJ, et al.; European Hidradenitis Suppurativa Foundation Investigator Group. Development and validation of the International Hidradenitis Suppurativa Severity Score System (IHS4), a novel dynamic scoring system to assess HS severity. Br J Dermatol. 2017 Nov; 177(5):1401-9.

3 Jemec GB. Clinical practice. Hidradenitis suppurativa. N Engl J Med. 2012 Jan;366(2): $158-64$.

4 Kirsten N, Petersen J, Hagenström K, Augustin M. Epidemiology of hidradenitis suppurativa in Germany - an observational cohort study based on a multisource approach. J Eur Acad Dermatol Venereol. 2020 Jan;34(1):174-9.

5 Revuz JE, Canoui-Poitrine F, Wolkenstein P, Viallette C, Gabison G, Pouget F, et al. Prevalence and factors associated with hidradenitis suppurativa: results from two case-control studies. J Am Acad Dermatol. 2008 Oct;59(4): 596-601.

6 Jemec GB, Heidenheim M, Nielsen NH. The prevalence of hidradenitis suppurativa and its potential precursor lesions. J Am Acad Dermatol. 1996 Aug;35(2 Pt 1):191-4.

7 Gasparic J, Theut Riis P, Jemec GB. Recognizing syndromic hidradenitis suppurativa: a review of the literature. J Eur Acad Dermatol Venereol. 2017 Nov;31(11):1809-16.

8 McDermott MF, Aksentijevich I, Galon J, McDermott EM, Ogunkolade BW, Centola $\mathrm{M}$, et al. Germline mutations in the extracellular domains of the $55 \mathrm{kDa}$ TNF receptor, TNFR1, define a family of dominantly inherited autoinflammatory syndromes. Cell. 1999 Apr;97(1):133-44.

9 Ciccarelli F, De Martinis M, Ginaldi L. An update on autoinflammatory diseases. Curr Med Chem. 2014;21(3):261-9.
10 Leuenberger M, Berner J, Di Lucca J, Fischer L, Kaparos N, Conrad C, et al. PASS Syndrome: An IL-1-Driven Autoinflammatory Disease. Dermatology. 2016;232(2):254-8.

11 Contassot E, Beer HD, French LE. Interleukin-1, inflammasomes, autoinflammation and the skin. Swiss Med Wkly. 2012 May; 142(MAY):w13590.

12 Kastner DL, Aksentijevich I, Goldbach-Mansky R. Autoinflammatory disease reloaded: a clinical perspective. Cell. 2010 Mar;140(6): 784-90.

13 Dessinioti C, Katsambas A, Antoniou C. Hidradenitis suppurativa (acne inversa) as a systemic disease. Clin Dermatol. 2014 May-Jun; 32(3):397-408.

14 Marzano AV, Damiani G, Ceccherini I, Berti E, Gattorno M, Cugno M. Autoinflammation in pyoderma gangrenosum and its syndromic form (pyoderma gangrenosum, acne and suppurative hidradenitis). Br J Dermatol. 2017 Jun;176(6):1588-98.

15 Marzano AV, Borghi A, Meroni PL, Cugno M. Pyoderma gangrenosum and its syndromic forms: evidence for a link with autoinflammation. Br J Dermatol. 2016 Nov; 175(5):88291.

16 Dinarello CA. Interleukin-1 in the pathogenesis and treatment of inflammatory diseases. Blood. 2011 Apr;117(14):3720-32.

17 Cugno M, Borghi A, Marzano AV. PAPA, PASH and PAPASH Syndromes: Pathophysiology, Presentation and Treatment. Am J Clin Dermatol. 2017 Aug;18(4):555-62.

18 Marzano AV, Borghi A, Wallach D, Cugno M. A Comprehensive Review of Neutrophilic Diseases. Clin Rev Allergy Immunol. 2018 Feb;54(1):114-30.

19 Marzano AV, Ortega-Loayza AG, Heath M, Morse D, Genovese G, Cugno M. Mechanisms of inflammation in neutrophil-mediated skin diseases. Front Immunol. 2019 May; 10:1059.
20 Marzano AV, Fanoni D, Antiga E, Quaglino P, Caproni M, Crosti C, et al. Expression of cytokines, chemokines and other effector molecules in two prototypic autoinflammatory skin diseases, pyoderma gangrenosum and Sweet's syndrome. Clin Exp Immunol. 2014 Oct; $178(1): 48-56$.

21 Mankan AK, Dau T, Jenne D, Hornung V. The NLRP3/ASC/Caspase-1 axis regulates IL$1 \beta$ processing in neutrophils. Eur J Immunol. 2012 Mar;42(3):710-5.

22 Guma M, Ronacher L, Liu-Bryan R, Takai S, Karin M, Corr M. Caspase 1-independent activation of interleukin-1 $\beta$ in neutrophil-predominant inflammation. Arthritis Rheum. 2009 Dec;60(12):3642-50.

23 Mitroulis I, Kourtzelis I, Kambas K, Rafail S, Chrysanthopoulou A, Speletas M, et al. Regulation of the autophagic machinery in human neutrophils. Eur J Immunol. 2010 May;40(5): 1461-72.

24 Donetti E, Cornaghi L, Gualerzi A, Baruffaldi Preis FW, Prignano F. An innovative three-dimensional model of normal human skin to study the proinflammatory psoriatic effects of tumor necrosis factor-alpha and interleukin-17. Cytokine. 2014 Jul;68(1):18.

25 Moran B, Sweeney CM, Hughes R, Malara A, Kirthi S, Tobin AM, et al. Hidradenitis Suppurativa Is Characterized by Dysregulation of the Th17:Treg Cell Axis, Which Is Corrected by Anti-TNF Therapy. J Invest Dermatol. 2017 Nov;137(11):2389-95.

26 Negus D, Ahn C, Huang W. An update on the pathogenesis of hidradenitis suppurativa: implications for therapy. Expert Rev Clin Immunol. 2018 Apr;14(4):275-83.

27 Caproni M, Antiga E, Volpi W, Verdelli A, Venegoni L, Quaglino P, et al. The Treg/Th17 cell ratio is reduced in the skin lesions of patients with pyoderma gangrenosum. Br J Dermatol. 2015 Jul;173(1):275-8. 
28 Vural S, Gundogdu M, Kundakci N, Ruzicka T. Familial Mediterranean fever patients with hidradenitis suppurativa. Int J Dermatol. 2017 Jun;56(6):660-3.

29 Abbara S, Georgin-Lavialle S, Stankovic Stojanovic K, Bachmeyer C, Senet P, Buob D, et al. Association of hidradenitis suppurativa and familial Mediterranean fever: A case series of 6 patients. Joint Bone Spine. 2017 Mar; 84(2):159-62.

30 Hodak E, Atzmony L, Pavlovsky L, Comaneshter D, Cohen A. Hidradenitis suppurativa is associated with familial Mediterranean fever: A population-based study. Exp Dermatol. 2016;25:16.

31 Join-Lambert O, Duchatelet S, Delage M, Miskinyte S, Coignard H, Lemarchand N, et al. Remission of refractory pyoderma gangrenosum, severe acne, and hidradenitis suppurativa (PASH) syndrome using targeted antibiotic therapy in 4 patients. J Am Acad Dermatol. 2015 Nov;73(5 Suppl 1):S66-9.

32 Duchatelet S, Miskinyte S, Join-Lambert O, Ungeheuer MN, Francès C, Nassif A, et al First nicastrin mutation in PASH (pyoderma gangrenosum, acne and suppurative hidradenitis) syndrome. Br J Dermatol. 2015 Aug; 173(2):610-2.

33 Faraji Zonooz M, Sabbagh-Kermani F, Fattahi Z, Fadaee M, Akbari MR, Amiri R, et al. Whole Genome Linkage Analysis Followed by Whole Exome Sequencing Identifies Nicastrin (NCSTN) as a Causative Gene in a Multiplex Family with $\gamma$-Secretase Spectrum of Autoinflammatory Skin Phenotypes. J Invest Dermatol. 2016 Jun;136(6):1283-6.

34 Zouboulis CC, Desai N, Emtestam L, Hunger RE, Ioannides D, Juhász I, et al. European S1 guideline for the treatment of hidradenitis suppurativa/acne inversa. J Eur Acad Dermatol Venereol. 2015 Apr;29(4):619-44.

35 Marzano AV, Ceccherini I, Gattorno M, Fanoni D, Caroli F, Rusmini M, et al. Association of pyoderma gangrenosum, acne, and suppurative hidradenitis (PASH) shares genetic and cytokine profiles with other autoinflammatory diseases. Medicine (Baltimore). 2014 Dec;93(27):e187.

36 Mizutani Y, Okano T, Takahashi T, Ohnishi $\mathrm{H}$, Ohara O, Sano A, et al. Pyoderma gangrenosum, acne and suppurative hidradenitis syndrome treated with granulocyte and monocyte adsorption apheresis. Acta Derm Venereol. 2017 Feb;97(2):275-6.

37 Ead J, Snyder RJ, Wise J, Cuffy C, Jafary H, Fischborn K. Is PASH Syndrome a Biofilm Disease?: A Case Series and Review of the Literature. Wounds. 2018 Aug;30(8):216-23.

38 Hsiao JL, Antaya RJ, Berger T, Maurer T, Shinkai K, Leslie KS. Hidradenitis suppurativa and concomitant pyoderma gangrenosum a case series and literature review. Arch Dermatol. 2010 Nov;146(11):1265-70.

39 Ah-Weng A, Langtry JA, Velangi S, Evans $\mathrm{CD}$, Douglas WS. Pyoderma gangrenosum associated with hidradenitis suppurativa. Clin Exp Dermatol. 2005 Nov;30(6):669-71.
40 Powell FC, Su WP, Perry HO. Pyoderma gangrenosum: classification and management. J Am Acad Dermatol. 1996 Mar;34(3):395409.

41 Marzano AV, Ishak RS, Colombo A, Caroli F, Crosti C. Pyoderma gangrenosum, acne and suppurative hidradenitis syndrome following bowel bypass surgery. Dermatology. 2012; 225(3):215-9.

42 Murphy B, Morrison G, Podmore P. Successful use of adalimumab to treat pyoderma gangrenosum, acne and suppurative hidradenitis (PASH syndrome) following colectomy in ulcerative colitis. Int J Colorectal Dis. 2015 Aug; 30(8):1139-40.

43 André MF, Piette JC, Kémény JL, Ninet J, Jego P, Delèvaux I, et al.; French Study Group on Aseptic Abscesses. Aseptic abscesses: a study of 30 patients with or without inflammatory bowel disease and review of the literature. Medicine (Baltimore). 2007 May;86(3):14561.

44 Saito N, Minami-Hori M, Nagahata H, Nozaki $\mathrm{H}$, Iinuma S, Igawa $\mathrm{S}$, et al. Novel PSTPIP1 gene mutation in pyoderma gangrenosum, acne and suppurative hidradenitis syndrome. J Dermatol. 2018 Aug;45(8):e213-4.

45 Jennings L, Molloy O, Quinlan C, Kelly G, O'Kane M. Treatment of pyoderma gangrenosum, acne, suppurative hidradenitis (PASH) with weight-based anakinra dosing in a Hepatitis B carrier. Int J Dermatol. 2017 Jun;56(6):e128-9.

46 Calderón-Castrat X, Bancalari-Díaz D, Román-Curto C, Romo-Melgar A, AmorósCerdán D, Alcaraz-Mas LA, et al. PSTPIP1 gene mutation in a pyoderma gangrenosum, acne and suppurative hidradenitis (PASH) syndrome. Br J Dermatol. 2016 Jul;175(1): 194-8.

47 Marzano AV, Trevisan V, Gattorno M, Ceccherini I, De Simone C, Crosti C. Pyogenic arthritis, pyoderma gangrenosum, acne, and hidradenitis suppurativa (PAPASH): a new autoinflammatory syndrome associated with a novel mutation of the PSTPIP1 gene. JAMA Dermatol. 2013 Jun;149(6):762-4

48 Starnes TW, Bennin DA, Bing X, Eickhoff JC, Grahf DC, Bellak JM, et al. The F-BAR protein PSTPIP1 controls extracellular matrix degradation and filopodia formation in macrophages. Blood. 2014 Apr;123(17):2703-14.

49 Holzinger D, Roth J. Alarming consequences - autoinflammatory disease spectrum due to mutations in proline-serine-threonine phosphatase-interacting protein 1. Curr Opin Rheumatol. 2016 Sep;28(5):550-9.

50 Hurtado-Nedelec M, Chollet-Martin S, Chapeton D, Hugot JP, Hayem G, Gérard B. Genetic susceptibility factors in a cohort of 38 patients with SAPHO syndrome: a study of PSTPIP2, NOD2, and LPIN2 genes. J Rheumatol. 2010 Feb;37(2):401-9.

51 Satoh T, Otsuka A, Contassot E, French LE. The inflammasome and IL- $1 \beta$ : implications for the treatment of inflammatory diseases. Immunotherapy. 2015;7(3):243-54.
52 Pink AE, Simpson MA, Desai N, Dafou D, Hills A, Mortimer P, et al. Mutations in the $\gamma$-secretase genes NCSTN, PSENEN, and PSEN1 underlie rare forms of hidradenitis suppurativa (acne inversa). J Invest Dermatol. 2012 Oct;132(10):2459-61.

53 Miskinyte S, Nassif A, Merabtene F, Ungeheuer $\mathrm{MN}$, Join-Lambert $\mathrm{O}$, Jais JP, et al. Nicastrin mutations in French families with hidradenitis suppurativa. J Invest Dermatol. 2012 Jun;132(6):1728-30.

54 Sonbol H, Duchatelet S, Miskinyte S, Bonsang B, Hovnanian A, Misery L. PASH syndrome (pyoderma gangrenosum, acne and hidradenitis suppurativa): a disease with genetic heterogeneity. $\mathrm{Br}$ J Dermatol. 2018 Jan; 178(1):e17-8

55 Raynor A, Askari AD. Behçet's disease and treatment with colchicine. J Am Acad Dermatol. 1980 May;2(5):396-400.

56 Abid N, Opran A, Rosner F. Hidradenitis suppurativa complicated by erosive arthropathy and ulcerative keratitis. J Clin Rheumatol. 1999 Feb;5(1):29-31.

57 Bruzzese V. Pyoderma gangrenosum, acne conglobata, suppurative hidradenitis, and axial spondyloarthritis: efficacy of anti-tumor necrosis factor a therapy. J Clin Rheumatol. 2012 Dec;18(8):413-5.

58 Saraceno R, Babino G, Chiricozzi A, Zangrilli A, Chimenti S. PsAPASH: a new syndrome associated with hidradenitis suppurativa with response to tumor necrosis factor inhibition. J Am Acad Dermatol. 2015 Jan;72(1):e42-4.

59 Gottlieb J, Madrange M, Gardair C, Sbidian E, Frazier A, Wolkenstein P, et al. PAPASH, PsAPASH and PASS autoinflammatory syndromes: phenotypic heterogeneity, common biological signature and response to immunosuppressive regimens. Br J Dermatol. 2019 Oct;181(4):866-9.

60 Richette P, Molto A, Viguier M, Dawidowicz K, Hayem G, Nassif A, et al. Hidradenitis suppurativa associated with spondyloarthritis results from a multicenter national prospective study. J Rheumatol. 2014 Mar;41(3):4904.

61 Miller IM, McAndrew RJ, Hamzavi I. Prevalence, Risk Factors, and Comorbidities of Hidradenitis Suppurativa. Dermatol Clin. 2016 Jan;34(1):7-16.

62 Rosner IA, Richter DE, Huettner TL, Kuffner GH, Wisnieski JJ, Burg CG. Spondyloarthropathy associated with hidradenitis suppurative and acne conglobata. Ann Intern Med. 1982 Oct;97(4):520-5.

63 Fimmel S, Zouboulis CC. Comorbidities of hidradenitis suppurativa (acne inversa). Dermatoendocrinol. 2010 Jan;2(1):9-16.

64 van der Zee HH, van der Woude CJ, Florencia EF, Prens EP. Hidradenitis suppurativa and inflammatory bowel disease: are they associated? Results of a pilot study. Br J Dermatol. 2010 Jan;162(1):195-7. 
65 Janse IC, Koldijk MJ, Spekhorst LM, Vila AV, Weersma RK, Dijkstra G, et al. Identification of Clinical and Genetic Parameters Associated with Hidradenitis Suppurativa in Inflammatory Bowel Disease. Inflamm Bowel Dis. 2016 Jan;22(1):106-13.

66 Rosi YL, Lowe L, Kang S. Treatment of hidradenitis suppurativa with infliximab in a patient with Crohn's disease. J Dermatolog Treat. 2005 Feb;16(1):58-61.

67 Saygin D, Syed AU, Lowder CY, Srivastava S, Maya JJ, Hajj-Ali RA. Characteristics of inflammatory eye disease associated with hidradenitis suppurativa. Eur J Rheumatol. 2018 Sep;5(3):165-8.

68 Lamiaux M, Dabouz F, Wantz M, Lebas D, Lasek A, Courivaud D, et al. Successful combined antibiotic therapy with oral clindamycin and oral rifampicin for pyoderma gangrenosum in patient with PASH syndrome. JAAD Case Rep. 2017 Dec;4(1):17-21.

69 Nikolakis G, Join-Lambert O, Karagiannidis I, Guet-Revillet H, Zouboulis CC, Nassif A. Bacteriology of hidradenitis suppurativa/ acne inversa: A review. J Am Acad Dermatol. 2015 Nov;73(5 Suppl 1):S12-8.

70 Nikolakis G, Liakou AI, Bonovas S, Seltmann $\mathrm{H}$, Bonitsis N, Join-Lambert $\mathrm{O}$, et al. Bacterial colonization in hidradenitis suppurativa/acne inversa: A cross-sectional study of 50 patients and review of the literature. Acta Derm Venereol. 2017 Apr;97(4):493-8.

71 Mansouri P, Hesami Z, Hajiha N, Chalangari A, Chalangari KM, Azizian Z. PASH Syndrome. The First Case Report from Iran. J Skin Stem Cell. 2019;5(4):4-6.

72 Garzorz N, Papanagiotou V, Atenhan A, Andres C, Eyerich S, Eyerich K, et al. Pyoderma gangrenosum, acne, psoriasis, arthritis and suppurative hidradenitis (PAPASH)-syndrome: a new entity within the spectrum of autoinflammatory syndromes? J Eur Acad Dermatol Venereol. 2016 Jan;30(1):141-3.

73 Gottlieb A, Menter A, Armstrong A, Ocampo C, Gu Y, Teixeira HD. Adalimumab Treatment in Women With Moderate-to-Severe Hidradenitis Suppurativa from the PlaceboControlled Portion of a Phase 2, Randomized, Double-Blind Study. J Drugs Dermatol. 2016 Oct;15(10):1192-6.

74 Grant A, Gonzalez T, Montgomery MO, Cardenas V, Kerdel FA. Infliximab therapy for patients with moderate to severe hidradenitis suppurativa: a randomized, doubleblind, placebo-controlled crossover trial. J Am Acad Dermatol. 2010 Feb;62(2):205-17.

75 Brooklyn TN, Dunnill MG, Shetty A, Bowden JJ, Williams JD, Griffiths CE, et al. Infliximab for the treatment of pyoderma gangrenosum: a randomised, double blind, placebo controlled trial. Gut. 2006 Apr;55(4):505-9.

76 Lim DT, James NM, Hassan S, Khan MA. Spondyloarthritis associated with acne conglobata, hidradenitis suppurativa and dissecting cellulitis of the scalp: a review with illustrative cases. Curr Rheumatol Rep. 2013 Aug; 15(8):346.
77 Katsanos KH, Christodoulou DK, Tsianos EV. Axillary hidradenitis suppurativa successfully treated with infliximab in a Crohn's disease patient. Am J Gastroenterol. 2002 Aug;97(8):2155-6.

78 Kimball AB, Okun MM, Williams DA, Gottlieb AB, Papp KA, Zouboulis CC, et al. Two phase 3 trials of adalimumab for hidradenitis suppurativa. N Engl J Med. 2016 Aug;375(5): 422-34.

79 Zouboulis CC, Okun MM, Prens EP, Gniadecki R, Foley PA, Lynde C, et al. Longterm adalimumab efficacy in patients with moderate-to-severe hidradenitis suppurati$\mathrm{va} / \mathrm{acne}$ inversa: 3 -year results of a phase 3 open-label extension study. J Am Acad Dermatol. 2019 Jan;80(1):60-69.e2.

80 Zouboulis CC. Adalimumab for the treatment of hidradenitis suppurativa/acne inversa. Expert Rev Clin Immunol. 2016 Oct; 12(10):1015-26.

81 Faleri S, Feichtner K, Ruzicka T. Schwere Akne bei Autoinflammationskrankheiten. Hautarzt. 2016 Nov;67(11):897-901.

82 Menis D, Maroñas-Jiménez L, Delgado-Marquez AM, Postigo-Llorente C, VanaclochaSebastián F. Two cases of severe hidradenitis suppurativa with failure of anakinra therapy. Br J Dermatol. 2015 Mar;172(3):810-1.

83 Braun-Falco M, Kovnerystyy O, Lohse P, Ruzicka T. Pyoderma gangrenosum, acne, and suppurative hidradenitis (PASH) - a new autoinflammatory syndrome distinct from PAPA syndrome. J Am Acad Dermatol. 2012 Mar;66(3):409-15.

84 Leslie KS, Tripathi SV, Nguyen TV, Pauli M, Rosenblum MD. An open-label study of anakinra for the treatment of moderate to severe hidradenitis suppurativa. J Am Acad Dermatol. 2014 Feb;70(2):243-51.

85 Gracia-Cazaña T, Frias M, Roselló R, VeraÁlvarez J, Gilaberte Y. PASH syndrome associated with osteopoikilosis. Int J Dermatol. 2015 Sep;54(9):e369-71.

86 Chamot AM, Benhamou CL, Kahn MF, Beraneck L, Kaplan G, Prost A. Acne-pustulosishyperostosis-osteitis syndrome. Results of a national survey. 85 cases. Rev Rhum Mal Osteoartic. 1987 Mar;54(3):187-96. French.

87 Nguyen MT, Borchers A, Selmi C, Naguwa SM, Cheema G, Gershwin ME. The SAPHO syndrome. Semin Arthritis Rheum. 2012 Dec; 42(3):254-65.

88 Hayem G, Bouchaud-Chabot A, Benali K, Roux S, Palazzo E, Silbermann-Hoffman O, et al. SAPHO syndrome: a long-term follow-up study of 120 cases. Semin Arthritis Rheum. 1999 Dec;29(3):159-71.

89 Colina M, Govoni M, Orzincolo C, Trotta F. Clinical and radiologic evolution of synovitis, acne, pustulosis, hyperostosis, and osteitis syndrome: a single center study of a cohort of 71 subjects. Arthritis Rheum. 2009 Jun;61(6): $813-21$.
90 Depasquale R, Kumar N, Lalam RK, Tins BJ Tyrrell PN, Singh J, et al. SAPHO: what radiologists should know. Clin Radiol. 2012 Mar;67(3):195-206.

91 Freyschmidt J, Sternberg A. The bullhead sign: scintigraphic pattern of sternocostoclavicular hyperostosis and pustulotic arthroosteitis. Eur Radiol. 1998;8(5):807-12.

92 Khanna G, Sato TS, Ferguson P. Imaging of chronic recurrent multifocal osteomyelitis. Radiographics. 2009 Jul-Aug;29(4):115977.

93 Benhamou CL, Chamot AM, Kahn MF. Synovitis-acne-pustulosis hyperostosis-osteomyelitis syndrome (SAPHO). A new syndrome among the spondyloarthropathies? Clin Exp Rheumatol. 1988 Apr-Jun;6(2): 109-12.

94 Cianci F, Zoli A, Gremese E, Ferraccioli G. Clinical heterogeneity of SAPHO syndrome: challenging diagnose and treatment. Clin Rheumatol. 2017 Sep;36(9):2151-8.

95 Jansson A, Renner ED, Ramser J, Mayer A, Haban M, Meindl A, et al. Classification of non-bacterial osteitis: retrospective study of clinical, immunological and genetic aspects in 89 patients. Rheumatology (Oxford). 2007 Jan;46(1):154-60.

96 De Souza A, Solomon GE, Strober BE. SA$\mathrm{PHO}$ syndrome associated with hidradenitis suppurativa successfully treated with infliximab and methotrexate. Bull NYU Hosp Jt Dis. 2011;69(2):185-7.

97 Burgemeister LT, Baeten DL, Tas SW. Biologics for rare inflammatory diseases: TNF blockade in the SA PHO syndrome. Neth J Med. 2012 Dec;70(10):444-9.

98 Crowley EL, O’Toole A, Gooderham MJ. Hidradenitis suppurativa with SAPHO syndrome maintained effectively with adalimumab, methotrexate, and intralesional corticosteroid injections. SAGE Open Med Case Rep. 2018 Jun;6:2050313X18778723.

99 Genovese G, Caorsi R, Moltrasio C, Marzano AV. Successful treatment of co-existent SAPHO syndrome and hidradenitis suppurativa with adalimumab and methotrexate. J Eur Acad Dermatol Venereol. 2019 Oct; 33(Suppl 6):40-1.

100 Vekic DA, Woods J, Lin P, Cains GD. SA$\mathrm{PHO}$ syndrome associated with hidradenitis suppurativa and pyoderma gangrenosum successfully treated with adalimumab and methotrexate: a case report and review of the literature. Int J Dermatol. 2018 Jan;57(1): $10-8$.

101 Daoussis D, Konstantopoulou G, Kraniotis $\mathrm{P}$, Sakkas L, Liossis SN. Biologics in SAPHO syndrome: A systematic review. Semin Arthritis Rheum. 2019 Feb;48(4):618-25.

102 Aytekin S, Uçmak D, Ayhan E, Fidan V. A new patient with pyoderma gangrenosum, acne, and suppurative hidradenitis (PASH) syndrome: case report. Turkiye Klin Dermatoloji. 2013;23(2):73-6 
103 Koshelev MV, Garrison PA, Wright TS. Concurrent hidradenitis suppurativa, inflammatory acne, dissecting cellulitis of the scalp, and pyoderma gangrenosum in a 16-year-old boy. Pediatr Dermatol. 2014 Jan-Feb;31(1):e20-1.

104 Staub J, Pfannschmidt N, Strohal R, BraunFalco M, Lohse P, Goerdt S, et al. Successful treatment of PASH syndrome with infliximab, cyclosporine and dapsone. J Eur Acad Dermatol Venereol. 2015 Nov;29(11):22437.

105 Zivanovic D, Masirevic I, Ruzicka T, BraunFalco M, Nikolic M. Pyoderma gangrenosum, acne, suppurative hidradenitis (PASH) and polycystic ovary syndrome: coincidentally or aetiologically connected? Australas J Dermatol. 2017 May;58(2):e54-9.

106 Wargo JJ, Emmer BT. Systemic Inflammation Gone Awry: PASH Syndrome and Temporomandibular Joint Ankylosis. Am J Med. 2016 Apr;129(4):e1-3.

107 Ursani MA, Appleyard J, Whiteru O. Pyogenic arthritis, pyoderma gangrenosum, acne, suppurative hidradenitis (PA-PASH) syndrome: an atypical presentation of a rare syndrome. Am J Case Rep. 2016 Aug;17: 587-91.

108 Niv D, Ramirez JA, Fivenson DP. Pyoderma gangrenosum, acne, and hidradenitis suppurativa $(\mathrm{PASH})$ syndrome with recurrent vasculitis. JAAD Case Rep. 2017 Feb;3(1): 70-3.

109 de Wet J, Jordaan HF, Kannenberg SM, Tod B, Glanzmann B, Visser WI. Pyoderma gangrenosum, acne, and suppurative hidradenitis syndrome in end-stage renal disease successfully treated with adalimumab. Dermatol Online J. 2017 Dec;23(12):13030/ qt82d $4 \mathrm{~m} 2 \mathrm{zw}$.
110 McCarthy S, Foley CC, Dvorakova V, Quinlan C, Murphy M, Maher M. PASH syndrome with bony destruction. Clin Exp Dermatol. 2019 Dec;44(8):918-20.

111 Gadelha R de L, Paiva R da SR, Palitot EB, Costa JEF da. PsAPASH: a rare and recent autoinflammatory syndrome associated with hidradenitis suppurativa. An Bras Dermatol. Mar-Apr 2020;95(2):203-6.

112 Boyd AS, Zemtsov A. A case of pyoderma vegetans and the follicular occlusion triad. J Dermatol. 1992 Jan;19(1):61-3.

113 Hamoir XL, François RJ, Van den Haute V, Van Campenhoudt M. Arthritis and hidradenitis suppurativa diagnosed in a 48-yearold man. Skeletal Radiol. 1999 Aug;28(8): 453-6.

114 Leybishkis B, Fasseas P, Ryan KF, Roy R. Hidradenitis suppurativa and acne conglobata associated with spondyloarthropathy. Am J Med Sci. 2001 Mar;321(3):195-7.

115 Roussomoustakaki M, Dimoulios P, Chatzicostas C, Kritikos HD, Romanos J, Panayiotides JG, et al. Hidradenitis suppurativa associated with Crohn's disease and spondyloarthropathy: response to anti-TNF therapy. J Gastroenterol. 2003;38(10):1000-4.

116 Thein M, Hogarth MB, Acland K. Seronegative arthritis associated with the follicular occlusion triad. Clin Exp Dermatol. 2004 Sep;29(5):550-2.

117 Tallo R, Quinet R, Waxman J. Reactive arthritis due to hidradenitis suppurativa mimicking osteomyelitis. South Med J. 1991 Sep; 84(9):1147-9.

118 Moschella SL. Is there a role for infliximab in the current therapy of hidradenitis suppurativa? A report of three treated cases. Int J Dermatol. 2007 Dec;46(12):1287-91.

119 Sahin MT, Oztürkcan S, Türel-Ermertcan A, Yurtman-Havlucu D, Bilaç C. Behçet's disease associated with hidradenitis suppurativa. J Eur Acad Dermatol Venereol. 2007 Mar;21(3):428-9.
120 Baerveldt EM, Kappen JH, Thio HB, van Laar JA, van Hagen PM, Prens EP. Successful long-term triple disease control by ustekinumab in a patient with Behcet's disease, psoriasis and hidradenitis suppurativa. Ann Rheum Dis. 2013 Apr;72(4):626-7.

121 Kirthi S, Hellen R, O'Connor R, Connolly M Tobin AM, McNamara D. Hidradenitis Suppurativa and Crohn's Disease: A Case Series. Ir Med J. 2017 Aug;110(7):618

122 Özyemisci-Taskiran O, Bölükbasi N, Gögüs F. A hidradenitis suppurativa related SAPHO case associated with features resembling spondylarthropathy and proteinuria. Clin Rheumatol. 2007 May;26(5):789-91.

123 Correia CP, Martins A, Oliveira J, Andrade S, Almeida J. Systemic Amyloidosis with Renal Failure: A Challenging Diagnosis of SAPHO Syndrome. Eur J Case Rep Intern Med. 2019 Mar;6(4):001087.

124 Bhosale P, Barron B, Lamki L. The "SAPHO" syndrome: a case report of a patient with unusual bone scan findings. Clin Nucl Med. 2001 Jul;26(7):619-21.

$125 \mathrm{Li} \mathrm{C}, \mathrm{Xu} \mathrm{H}$, Wang B. Is SAPHO syndrome linked to PASH syndrome and hidradenitis suppurativa by nicastrin mutation? a case report. J Rheumatol. 2018 Nov;45(11):1605-7.

126 Gmyrek R, Grossman ME, Rudin D, Scher R. SAPHO syndrome: report of three cases and review of the literature. Cutis. 1999 Oct; 64(4):253-8.

127 Kundu BK, Naik AK, Bhargava S, Srivastava D. Diagnosing the SAPHO syndrome: a report of three cases and review of literature. Clin Rheumatol. 2013 Aug;32(8):1237-43.

128 Steinhoff JP, Cilursu A, Falasca GF, Guzman L, Reginato AJ. A study of musculoskeletal manifestations in 12 patients with SAPHO syndrome. J Clin Rheumatol. $2002 \mathrm{Feb} ; 8(1)$ : 13-22. 